\title{
The nature and the mechanism of crack initiation and early growth for very-high-cycle fatigue of metallic materials - An overview
}

\author{
Youshi Hong*, Chengqi Sun \\ LNM, Institute of Mechanics, Chinese Academy of Sciences, Beijing 100190, China \\ School of Engineering Science, University of Chinese Academy of Sciences, Beijing 100049, China
}

\section{A R T I C L E I N F O}

\section{Article history:}

Received 31 March 2017

Revised 4 May 2017

Accepted 4 May 2017

Available online 15 May 2017

\section{Keywords:}

Very-high-cycle fatigue

Fatigue crack initiation

Fine-granular-area

Nanograins

High-strength steels

Titanium alloys

\begin{abstract}
A B S T R A C T
Very-high-cycle fatigue (VHCF) is the fatigue damage and failure beyond $10^{7}$ loading cycles. Crack initiation of VHCF for metallic materials is commonly from the interior of specimens and possesses a unique feature of fish-eye (FiE) containing a fine-granular-area (FGA). It is regarded that FGA together with FiE is the characteristic region of crack initiation for VHCF, because it consumes more than $95 \%$ of total fatigue life and the value of stress intensity factor range for this region keeps constant for a given material. The aim of this overview is to summarize the research progress on the crack initiation characteristics and the related mechanisms for VHCF of metallic materials. After a brief introduction to the origination of VHCF research in 1980s, this overview contains the following parts: Characteristics of crack initiation region for VHCF, Characteristic region and intrinsic dimensions of crack initiation for VHCF, The formation mechanism and the model of crack initiation region, The new model of Numerous Cyclic Pressing to explain the formation mechanism of FGA, and Verification of proposed NCP model. In the descriptions, the two essential aspects are especially focused: the nature of crack initiation region for VHCF, and the mechanism for the formation of crack initiation region.
\end{abstract}

(c) 2017 Elsevier Ltd. All rights reserved.

\section{Introduction}

Very-high-cycle fatigue (VHCF) of metallic materials is the fatigue failure beyond $10^{7}$ loading cycles [1], which was also called ultra-high-cycle fatigue [2], ultra-long-cycle fatigue [3] or gigacycle fatigue [4]. The research of VHCF is a challenge to the traditional fatigue concept that considers the existence of a fatigue limit for a metallic material at $10^{7}$ loading cycles [5]. No fatigue failure of the material will happen when it is subjected to a cyclic stress below this limit.

The earliest report of fatigue failure beyond $10^{7}$ cycles may date back to 1960s when Kikukawa et al. [6] presented the fatigue data of over $10^{8}$ failure cycles with ultrasonic loading frequencies, although they paid little attention to the characteristics of fatigue failure beyond $10^{7}$ cycles. In 1980s, it was seen the early specific investigations on VHCF phenomena, e.g. Naito et al. [7,8] on carburized steels and Atrens et al. [9] on titanium alloys.

Since 1980s, the topic of VHCF for metallic materials has attracted an increasing number of investigations and has become a new regime of fatigue research. The reasons are: on the one hand,

\footnotetext{
* Corresponding author at: LNM, Institute of Mechanics, Chinese Academy of Sciences, Beijing 100190, China.

E-mail address: hongys@imech.ac.cn (Y. Hong).
}

in engineering applications, including aircraft, high speed train, automobile, bridge, ship, etc., the related components and structures are required to endure up to $10^{10}$ loading cycles of safe performance; and on the other hand, the mechanism of crack initiation and early growth for VHCF differs from that for highcycle and low-cycle fatigue regimes, and has yet to be clearly revealed. It is worth noting that in the very early days of fatigue research, the concerned engineering issue was train axles [10]. After one and half centuries, the steam locomotive with the low speed of $10 \mathrm{~km}$ per hour has evolved to the high-speed train running over $300 \mathrm{~km}$ per hour. The axle for the latter will be subjected to the loading cycles in the magnitude of $10^{9}$ (whole service life), for which the concern of VHCF failure is regarded as one of the "difficulties and imponderables" [11].

The research of VHCF may be traced to the application of ultrasonic loading frequencies ( $\geq 20 \mathrm{kHz}$ ) in 1950 s and 1960s [12], which was to accelerate the testing process so as to investigate the fatigue properties at higher loading cycles and the crack behavior at lower propagation rate. A typical example by Kikukawa et al. [6] investigated the effects of loading frequency $(13-100 \mathrm{kHz})$ on fatigue properties of mild steels up to the failure cycles of $10^{9}$ and showed that higher frequency resulted in larger fatigue limit, in which the reasons of frequency effect and the features of VHCF were not mentioned. The article by Willertz [13] overviewed the 


$\begin{array}{ll}\text { Nomenclature } \\ \text { FCG } & \text { fast crack growth } \\ \text { FGA } & \text { fine-granular-area } \\ \text { FIB } & \text { focused ion beam } \\ \text { FiE } & \text { fish-eye } \\ \text { GBF } & \text { granular-bright-facet } \\ \text { HCF } & \text { high-cycle fatigue } \\ \text { NCP } & \text { numerous cyclic pressing } \\ \text { ODA } & \text { optical-dark-area } \\ \text { OM } & \text { optical microscopy } \\ \text { RSA } & \text { rough-surface-area } \\ \text { SAD } & \text { selected area electron diffraction } \\ \text { SCG } & \text { steady crack growth } \\ \text { SEM } & \text { scanning electron microscopy } \\ \text { SIF } & \text { stress intensity factor } \\ \text { VHCF } & \text { very-high-cycle fatigue } \\ 2 a_{\text {FGA }} & \text { equivalent FGA diameter } \\ 2 a_{\text {FiE }} & \text { equivalent FiE diameter } \\ 2 a_{\text {Inc }} & \text { equivalent inclusion diameter }\end{array}$

$\begin{array}{ll}\mathrm{d} a / \mathrm{d} N & \text { crack growth rate } \\ b & \text { magnitude of Burgers vector } \\ \Delta K & \text { SIF range } \\ \Delta K_{\mathrm{FGA}} & \text { SIF range for FGA } \\ K_{\mathrm{Imax}} & \text { maximum value of SIF } \\ l_{\mathrm{m}} & \text { characteristic dimension of material } \\ N_{\mathrm{f}} & \text { total fatigue life } \\ N_{\mathrm{i}} & \text { crack initiation life } \\ R & \text { stress ratio } \\ r_{\mathrm{p}} & \text { plastic zone size at crack tip } \\ \mu & \text { shear modulus } \\ v & \text { Poisson ratio } \\ \sigma_{\mathrm{a}} & \text { stress amplitude } \\ \sigma_{\mathrm{max}} & \text { maximum stress } \\ \sigma_{\mathrm{y}} & \text { yield strength }\end{array}$

$\mathrm{d} a / \mathrm{d} N \quad$ crack growth rate

$\Delta K_{\mathrm{FGA}} \quad$ SIF range for FGA

$K_{\text {Imax }}$ maximum value of SIF

$l_{\mathrm{m}} \quad$ characteristic dimension of material

$N_{\mathrm{f}} \quad$ total fatigue life

$N_{\mathrm{i}} \quad$ crack initiation life

$R \quad$ stress ratio

$r_{\mathrm{p}} \quad$ plastic zone size at crack tip

$\mu \quad$ shear modulus

$\sigma_{\mathrm{a}} \quad$ stress amplitude

$\sigma_{\mathrm{y}} \quad$ yield strength fatigue experimental investigations with ultrasonic frequencies for the period between 1950s and 1970s. The proceedings of "Ultrasonic Fatigue" [14] contained 40 papers represented the results in late 1970s and early 1980s, in which about a quarter of papers contained the data of failure cycles between $10^{7}$ and $10^{10}$, but the related mechanism was not investigated. In the keynote lecture [15] of this conference in 1981, the term of "very high cycle fatigue data" seemed the first time being used.

In early 1980 s, Naito et al. [7,8] obtained fatigue properties (via rotary bending) up to $10^{8}$ cycles of fatigue life for a carburized steel to show the two knees of the S-N curve: one located at about $10^{5}$ cycles and the other at $5 \times 10^{6}$ cycles. The fatigue strength decreased with loading cycles and no fatigue limit existed. They also noticed crack initiation from the subsurface of specimen with a typical feature of "fish-eye" on fracture surface for the specimens failed beyond $5 \times 10^{6}$ cycles. In the same period, Atrens et al. [9] reported the S-N data (via axial cycling) of a titanium alloy (Ti$6 \mathrm{Al}-4 \mathrm{~V}$ ), showing fatigue failure happened after $10^{7}$ cycles with fatigue strength decreasing with loading cycles and fatigue crack initiation site from specimen surface changed to specimen interior. A couple of years later, Asami et al. [16] also reported the fatigue data up to $10^{8}$ failure cycles for a carburized steel again showing two knee feature of the S-N curve and subsurface crack initiation with fish-eye morphology.

Naito et al. [7,8] and Atrens et al. [9] seemed the first time to report the fatigue properties and the fracture surface morphology of VHCF for high-strength steels and for titanium alloys, respectively, although they called this stage "long life fatigue" rather than "very high cycle fatigue". In 1986, Stanzl et al. [1] reported the fatigue failures (via $20 \mathrm{kHz}$ axial cycling) from $3 \times 10^{6}$ to $3 \times 10^{9}$ cycles for a low carbon steel and called this "very high cycle fatigue range", which seemed the first time to use the term "very high cycle fatigue" in a research paper.

The papers by Naito et al. [7,8], Atrens et al. [9], Asami et al. [16] and Stanzl et al. [1] between 1983 and 1986, signaled the beginning of VHCF research, for which the concerned propensities differed from those possessed by traditional low-cycle and highcycle fatigue regimes.

The advances of the research on VHCF have been summarized from different angles in several recent reviews, e.g. [17-23]. After the brief introduction to the origination of VHCF research, this overview will concentrate on the research progress in the characteristics of crack initiation and early growth for VHCF of metallic materials, and will focus on the cases of high-strength steels and titanium alloys. Especially the two essential aspects will be addressed: What is the nature of crack initiation region for VHCF? And what is the mechanism for the formation of crack initiation region?

\section{Characteristics of crack initiation region for VHCF}

\subsection{Cases of high-strength steels}

In the early investigations on carburized steels by Naito et al. [8], they observed the fish-eye (hereafter abbreviated as FiE) morphology (Fig. 1) at crack initiation region for the specimen without surface microstructure anomalies, which was the earliest observed FiE morphology of interior crack initiation for VHCF of highstrength steels. Thereafter, Asami et al. [16,24] also reported the subsurface crack initiation with FiE morphology for high-strength structural steels at high-cycle fatigue (HCF) and VHCF regimes. Nishijima et al. [25] summarized the results in the early period of 1980s and 1990s to show the tendency of crack initiation from surface or from subsurface of specimen with respect to the shape of S-N curves. They presumed that the condition required for crack

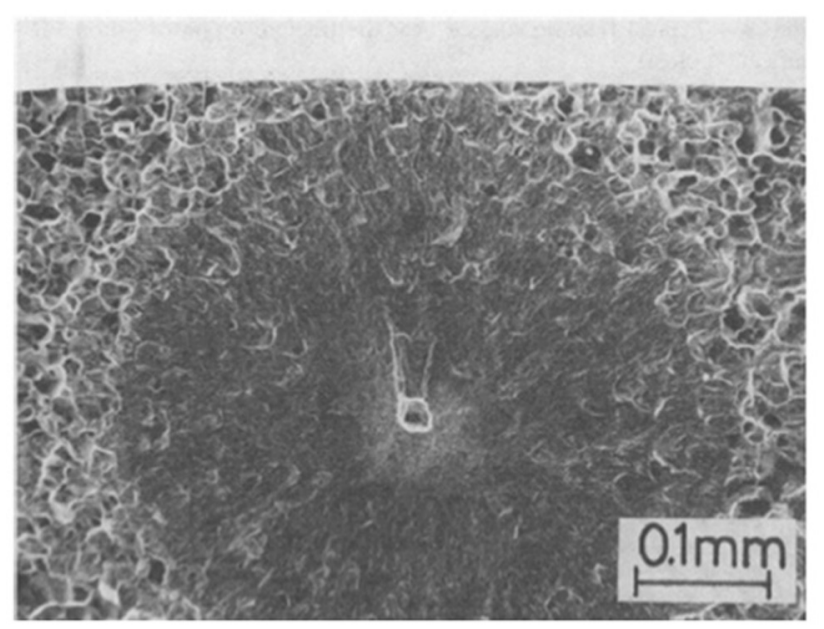

Fig. 1. Fatigue crack subsurface initiation with fish-eye feature [8]. 


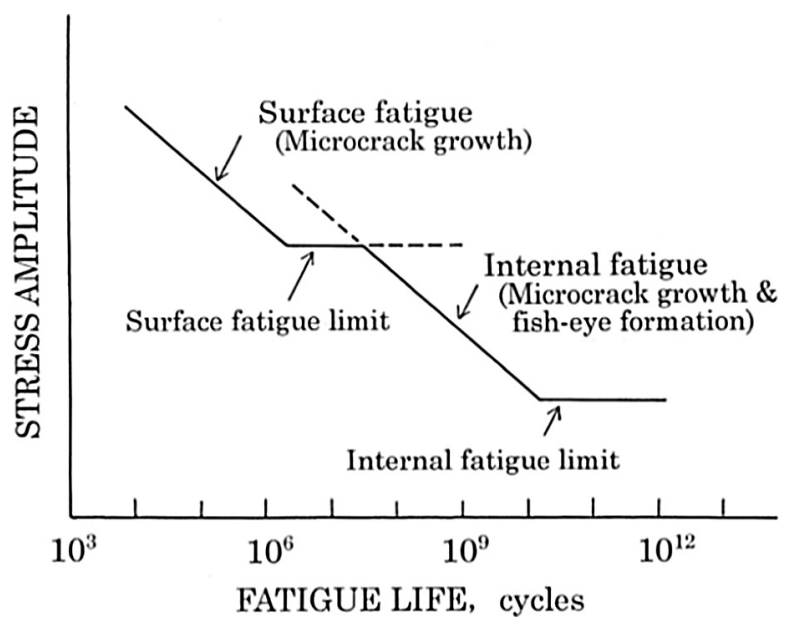

Fig. 2. Schematic of twofold S-N curves [25].

initiation from interior was lower that from surface, and only when surface initiation was restricted, the initiation from interior could happen, which resulted in the twofold style of S-N curves (Fig. 2).

Sakai et al. [26] reported a large number of S-N data from $10^{3}$ to $10^{9}$ failure cycles obtained by six laboratories with the same type of rotary bending machines $(52.5 \mathrm{~Hz})$ and the same type specimen ( $\Phi 3 \mathrm{~mm}$ ) of SUJ2 steel, and showed the S-N curves of twofold or duplex shape. They observed that for the specimens failed before $10^{6}$ cycles, crack initiation was from specimen surface, and for the specimens failed beyond $10^{6}$ and up to $10^{9}$ cycles, crack initia- tion was from specimen subsurface with FiE morphology (Fig. 3a). In the crack origination site, a relatively bright and rough region with the size of tens of microns was presented (Fig. 3b), which was called "Fine-Granular-Area (FGA)". Sakai et al. [27,28] also reported the S-N data from $10^{4}$ to $10^{9}$ failure cycles of SUJ2 steel via axial cycling $(50 \mathrm{~Hz})$ with the $\mathrm{S}-\mathrm{N}$ curve of single line tendency. For failure cycles between $10^{5}$ and $10^{9}$, fatigue crack initiated from specimen interior with FiE morphology containing an FGA (Fig. 4). For the case of axial cycling, crack interior initiation sites randomly distributed in the cross section of specimen, whereas for the case of rotary bending, crack initiation sites almost at the subsurface of specimen. This can be readily understood by the difference of stress distribution for the two cases: for the former the stress is uniformly distributed whereas for the latter the stress is the largest at the surface of specimen and declines to zero at the central point of cross section.

The crack initiation region (i.e. FGA) was also named opticaldark-area (ODA) by Murakami et al. [3], granular-bright-facet (GBF) by Shiozawa et al. [29], or rough surface area (RSA) by Ochi et al. [30]. Fig. 5 shows the morphology by optical microscopy (OM) and scanning electron microscopy (SEM) for crack subsurface initiation of a GCr15 steel (similar to SUJ2) in VHCF regime [31], where FiE is bright and FGA is dark in OM image (Fig. 5b), and FGA is relatively bright in SEM image (Fig. 5c).

Then we draw a schematic to demonstrate the VHCF process from crack initiation to final fracture (Fig. 6). That is, crack initiation at an inclusion from the interior of specimen, and early growth to form an FiE that contains a crack initiation region of FGA. The fracture surface of FGA is relatively rough, and the FiE region outside FGA is relatively flat. Beyond FiE the fracture surface is of large roughness, which is the crack steady growth region.
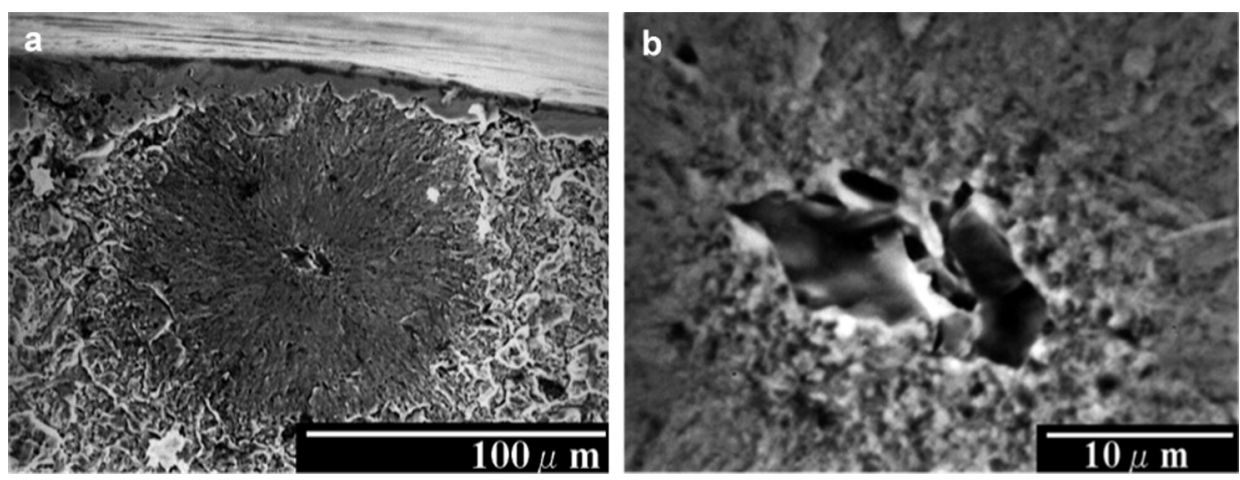

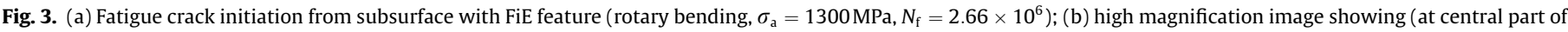
the FiE) an FGA surrounding an inclusion of crack origin [26]
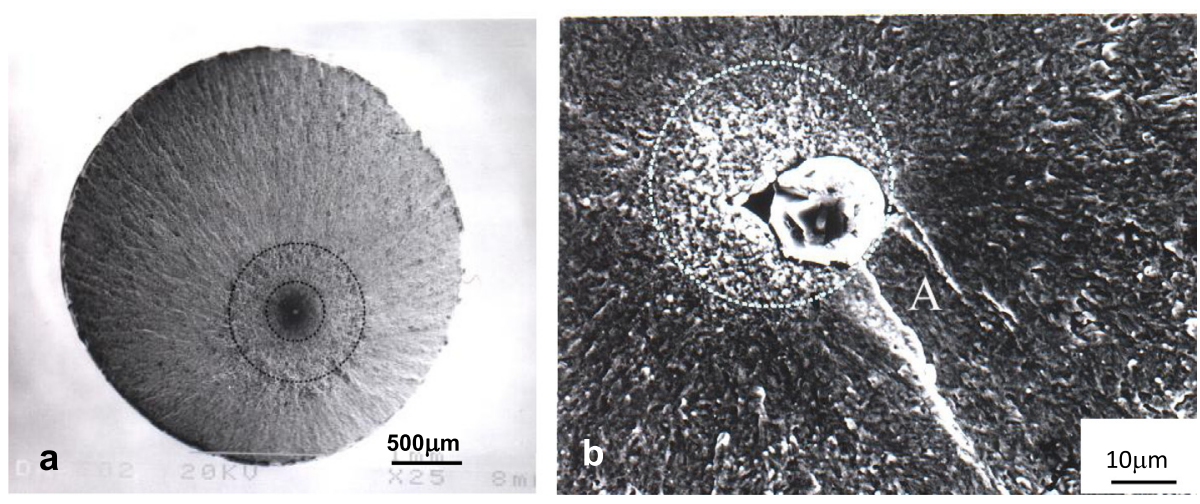


part of the FiE) an FGA surrounding an inclusion of crack origin [28]. 




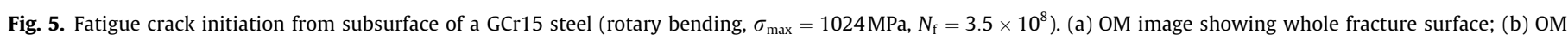
image showing FiE region and (c) SEM image showing FGA region [31].

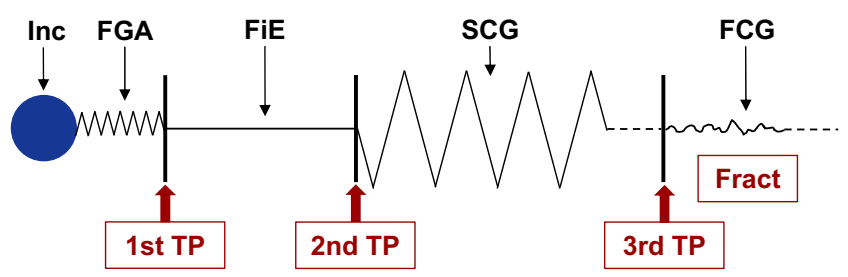

Fig. 6. Schematic showing whole VHCF process from crack initiation to final fracture of high-strength steels, Inc: Inclusion, FiE: Fish-eye, SCG: Steady crack growth, FCG: Fast crack growth, TP: Transition point. (In fact, FiE contains FGA, and here FiE just indicates the part outside FGA).

Regarding the roughness of fracture surface, Shiozawa et al. $[32,33]$ provided the results (Table 1 ) of FGA, FiE outside FGA and SCG outside FiE, which were obtained from a specimen (SUJ2) experienced $6.3 \times 10^{8}$ failure cycles via rotary bending. The data indicate that the average value of roughness Ra for FGA is 2.2 times of that for FiE, and the Ra value for SCG is 3.5 times of that for FiE. Another group of data [34] in Table 1 obtained from a structure steel $(0.4 \%$ $\mathrm{C}, 1.0 \% \mathrm{Cr}$ ) specimen experienced $1.34 \times 10^{7}$ failure cycles via rotary bending, show the Ra value for FGA is 3.4 times of that for FiE, and the $R$ a value for SCG is 3.9 times of that for FiE.

\subsection{Cases of titanium alloys}

Titanium alloys are almost free of inclusions and cavities. The microstructure feature of titanium alloys (e.g. Ti-6Al-4V) depends on the fraction and the shape of $\alpha$ phase (hcp lattice) and $\beta$ phase (bcc lattice). $\alpha$ phase is brittle in character. In VHCF process, cracks always initiate from the cleavage of $\alpha$ phase with facet morphology. The early investigation on Ti-6Al-4V by Atrens et al. [9] demonstrated that for fatigue life shorter than $10^{7}$ cycles, cracks initiated from specimen surface, whereas for fatigue life longer than $10^{7}$ cycles, cracks originated from subsurface or interior of specimen. For the effect of microstructure on VHCF behavior of Ti-6Al-4V, the work by Zuo et al. [35] concluded that for the failures ( $20 \mathrm{kHz}, R=-1)$ due to interior initiation, cracks initiated at primary $\alpha$ grain $\left(\alpha_{p}\right)$ boundaries or inside $\alpha_{p}$ grains in bimodal microstructure, and at $\alpha$ - $\beta$ interfaces or colonies in basket-weave microstructure. Another example by Szczepanski et al. [36] reported that for the VHCF $(20 \mathrm{kHz}, R=0.05)$ of Ti-6Al-2Sn-4Zr$6 \mathrm{Mo}$, cracks initiated from the interior of specimen, and the crack initiation sites were the morphology of distributed facets that formed from the cleavage of $\alpha_{\mathrm{p}}$ grains with the size larger than their average value. Facets in the initiation cites were high shear stress oriented with the orientation angle between facet normal and loading axis being about $45^{\circ}$. By using a conventional frequency of $120 \mathrm{~Hz}$ on Ti-6Al-4V with $R=0.1$, Oguma et al. [37] also presented similar observations of crack initiation from the interior of specimen at the failure cycles larger than $10^{7}$ with the initiation sites consisting of the facets resulted from the cleavage of $\alpha$ grains.

Another typical result on Ti-6Al-4V subjected to ultrasonic axial cycling $(20 \mathrm{kHz})$ at $R=-1$ by Heinz et al. [38] showed that there was a knee point at $2 \times 10^{7}$ failure cycles of S-N curve, beyond which crack initiation mode changed from surface to interior of

Table 1

Surface roughness of FGA, FiE and steady crack growth (SCG) regions.

\begin{tabular}{|c|c|c|c|c|c|c|}
\hline \multirow[t]{2}{*}{ Roughness } & \multicolumn{3}{|c|}{ SUJ2 [32,33] } & \multicolumn{3}{|c|}{$40 \mathrm{Cr}[34]$} \\
\hline & FGA & FiE & SCG & FGA & FiE & SCG \\
\hline$R_{\mathrm{a}}(\mu \mathrm{m})$ & 0.195 & 0.089 & 0.313 & 0.0379 & 0.0113 & 0.0554 \\
\hline$R_{\max }(\mu \mathrm{m})$ & 1.008 & 0.462 & 1.703 & 0.180 & 0.0705 & 0.311 \\
\hline
\end{tabular}



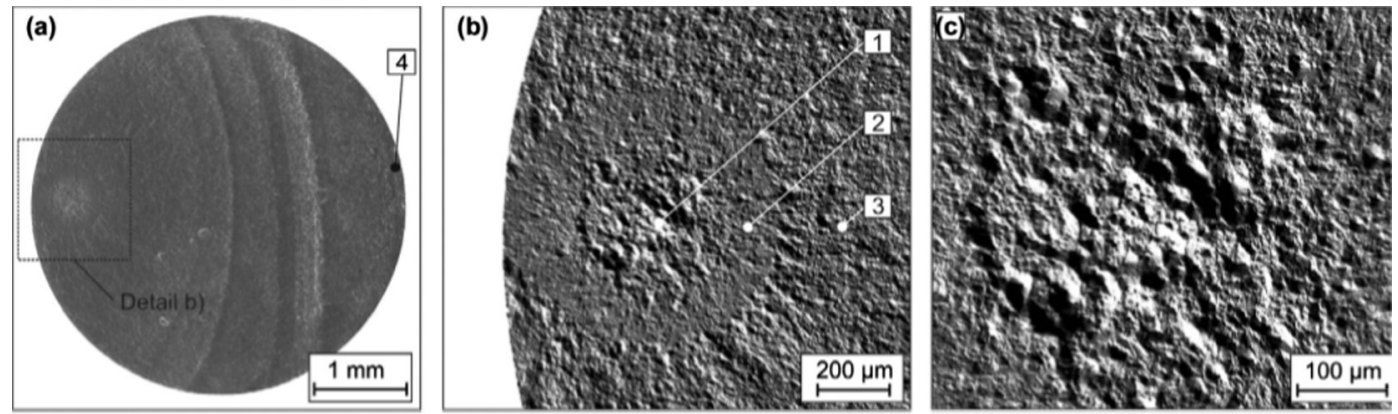

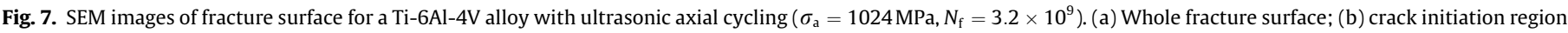
and (c) morphology of RA region " 1 " [38].



Fig. 8. Fatigue crack initiation from subsurface with FiE feature $(20 \mathrm{kHz}, R=-1$, $N_{\mathrm{f}}=2.10 \times 10^{8}$ ) for a Ti-6Al-4V alloy with equiaxed $\alpha$ phase [39].

specimen (Fig. 7). It is seen that crack initiation site is of FiE morphology ("2" in Fig. 7b), an FGA-like rough region is inside the FiE (" 1 " in Fig. 7b), and the detail of the rough region is shown in Fig. 7c.

Takeuchi et al. [39] and Furuya et al. [40] reported a series of S$\mathrm{N}$ data of Ti-6Al-4V with different microstructures tested by axial cycling at $120 \mathrm{~Hz}$ and $20 \mathrm{kHz}$. For a group of specimens with equiaxed $\alpha$ phase and the average grain size being $7 \mu \mathrm{m}$, fatigue crack initiated from the interior of specimen in HCF and VHCF regimes, and crack initiation region exhibited the morphology of FiE containing a rough area in its central part (Fig. 8). For another group of specimens with elongated microstructure in rolling direction and the average (equivalent) grain size being $20 \mu \mathrm{m}$, the interior initiated cracks were the clusters of facets (Fig. 9), and the size of each facet was about the average size of $\alpha$ grains.

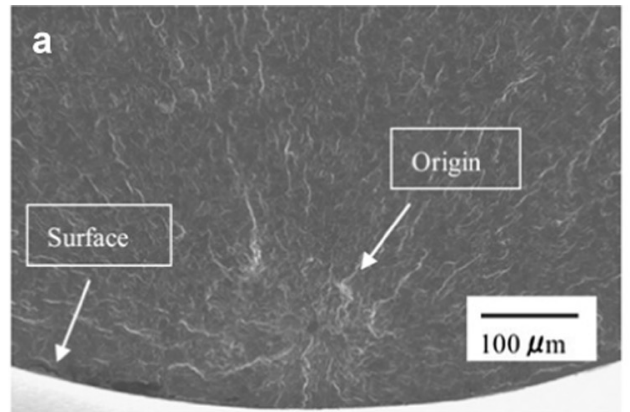

Recently, Liu et al. [41] obtained the VHCF properties at different stress ratios of Ti-6Al-4V. For $R=-0.1,0.1$ and 0.5 , fatigue cracks initiated from the interior of specimen at fatigue life beyond $10^{7}$ cycles; whereas for $R=-1$ and -0.5 , fatigue cracks initiated from specimen surface even at VHCF regime. Fig. 10 shows the three types of crack initiation modes: surface slip (Fig. 10a), surface cleavage (Fig. 10b) and interior cleavage (Fig. 10c).

Crack initiation of VHCF for titanium alloys is commonly associated with the cleavage of $\alpha$ phase and presents facet morphology. The coalescence of distributed facets forms the region of crack initiation. This region is of rough fracture surface and is regarded as Rough-area (RA) [41]. Fig. 11 is a schematic to demonstrate the whole process of VHCF for titanium alloys: crack initiation from RA containing facets to FiE, then to SCG and to final fracture. The recent result by Liu et al. [42] indicated that the roughness of facets was only $14 \mathrm{~nm}$, the value of the local area linking adjacent facets was $2217 \mathrm{~nm}$, and that of FiE region was $209 \mathrm{~nm}$; i.e. the roughness of RA was an order of magnitude larger than that of FiE region.

\section{Characteristic region and intrinsic dimensions of crack initiation for VHCF}

\subsection{Characteristic region for crack initiation of FGA and FiE}

The unique feature of crack initiation for VHCF of high-strength alloys is that fatigue cracks initiate from the interior of material or specimen, which is the essential point that differs from low-cycle fatigue and HCF cases. An interior initiated crack always exhibits an FiE morphology on fracture surface (Figs. 1, 3-5, 7, 8), which often contains a localized rough region in its central part. For high-strength steels, this region is called ODA, GBF, RSA or FGA. (Hereafter this region is termed FGA.) For Titanium alloys, this region is named RA. It was pointed out that FGA together with FiE is the characteristic region of VHCF for high-strength steels,

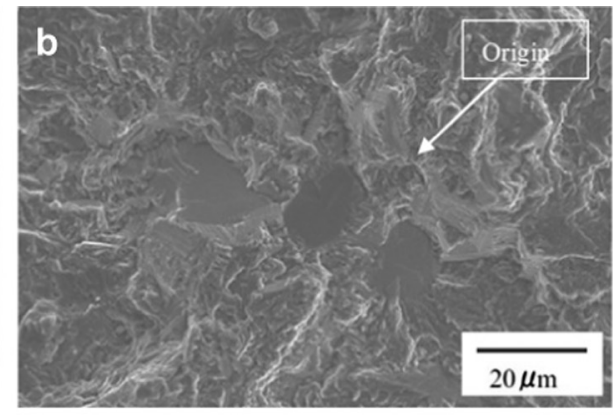

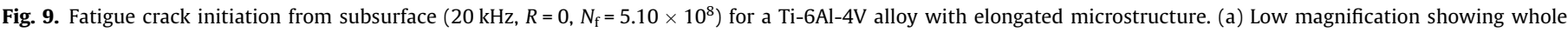
initiation region and (b) high magnification image showing facet morphology in the initiation region [40]. 



Fig. 10. (a) Surface slip induced crack initiation $\left(R=-1, \sigma_{\mathrm{a}}=550 \mathrm{MPa}, N_{\mathrm{f}}=1.13 \times 10^{7}\right)$; (b) surface cleavage induced crack initiation $\left(R=0.5, \sigma_{\mathrm{a}}=202 \mathrm{MPa}, N_{\mathrm{f}}=4.03 \times 10^{7}\right)$ and (c) interior cleavage induced crack initiation $\left(R=0.1, \sigma_{\mathrm{a}}=339 \mathrm{MPa}, N_{\mathrm{f}}=2.26 \times 10^{7}\right)$ [41].

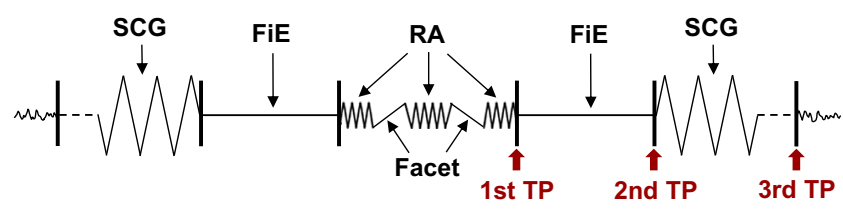

Fig. 11. Schematic showing whole VHCF process from crack initiation to final fracture of titanium alloys, RA: Rough area, FiE: Fish-eye, SCG: Steady crack growth, TP: Transition point, (In fact, FiE contains RA and facet, and here FiE just indicates the part outside RA).

and the related sizes are the characteristic dimensions of crack initiation for VHCF of high-strength steels [43]. The region of RA together with FiE for titanium alloys plays the same essential role in the VHCF process.

Fig. 12a shows typical images and Fig. 12b shows a schematic of the characteristic region for VHCF of high-strength steels [43]. It is clearly illustrated that fatigue crack initiates from an inclusion (Inc) in the interior of specimen, then an initiation region of FGA forms, next a region of FiE develops, and eventually the crack propagates to final fracture.

As schematically shown in Fig. 6, an FGA crack develops passing the first transition point to the region of FiE, and then it further develops passing the second transition point into the stage of steady crack growth. The fatigue life consumed by FGA is $N_{\mathrm{i}}$, that consumed by FiE is $N_{1}$ and that consumed by SCG is $N_{2}$. Here, special attention will be paid to the values for the region prior to the first transition point, i.e. FGA region.

It should be noted that, in the research of VHCF, the parameter of stress intensity factor (SIF) $K$ is commonly used in the description of crack initiation and growth. For this, Murakami et al. [44] provided the formulas of the maximum value of SIF $\left(K_{\text {Imax }}\right)$ for the problems of a crack originating from surface defect or from interior defect. For the case of crack originating from surface defect, the formula is:
$K_{\operatorname{Imax}}=0.65 \sigma_{0}\left(\pi \sqrt{\text { area }_{\mathrm{s}}}\right)^{1 / 2}$

where $\sigma_{0}$ is the maximum tensile stress, area $_{\mathrm{s}}$ is the projection area of surface defect on the plane perpendicular to tensile stress. For the case of crack originating from interior defect, the formula is:

$K_{\operatorname{Imax}}=0.5 \sigma_{0}\left(\pi \sqrt{\text { area }_{\mathrm{i}}}\right)^{1 / 2}$

where area $_{\mathrm{i}}$ is the projection area of interior defect on the plane perpendicular to tensile stress.

Note also that the similar type of SIF description was used in the fatigue limit assessment for the components with surface notches or defects by Atzori et al. [45].

\subsection{Characteristic quantities for characteristic region of FGA and FiE}

FGA together with FiE is the characteristic region of crack initiation for VHCF. The dimensions of FGA and FiE, and the related physical properties are characteristic quantities of this characteristic region.

The results obtained from SUJ2 steel with rotary bending by Sakai et al. [46] demonstrated that, the size of FGA decreased with the increase of cyclic stress (Fig. 13a) with the value of $\sqrt{\text { area }}$ of FGA ranging from 15 to $32 \mu \mathrm{m}$; whereas the size of the inclusion as crack origin was of little change with cyclic stress (Fig. 13a). The size of FiE covered a large range from 50 to $300 \mu \mathrm{m}$ [46].

The important point was that the value of SIF range $\Delta K$ did not change with loading cycles [46], i.e. it almost kept constant at an average of $4.74 \mathrm{MPa} \cdot \mathrm{m}^{1 / 2}$ between failure cycles from $10^{5}$ to $10^{9}$ (Fig. 13b), whereas the $\Delta K$ value for inclusions as crack origin decreased with the increase of fatigue cycles (Fig. 13b).

The similar results on SUJ2 steel by Shiozawa et al. [47] indicated that the size of FGA was between 12 and $40 \mu \mathrm{m}$ and the corresponding $\Delta K$ value was between 4 and $6 \mathrm{MPa} \cdot \mathrm{m}^{1 / 2}$.

A series of results on GCr15 steel (similar to SUJ2) via rotary bending and ultrasonic axial cycling by Zhao et al. [48,49] also
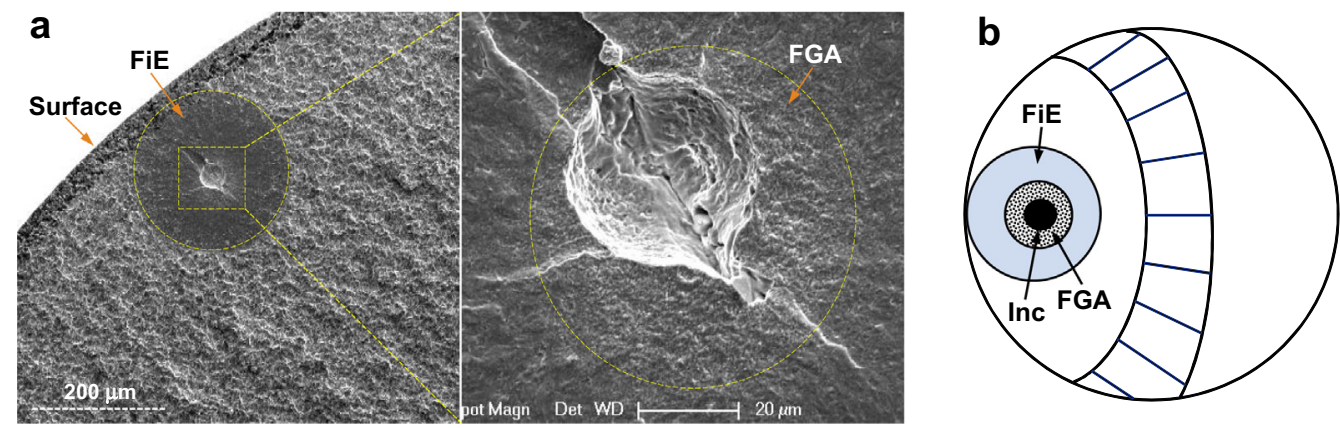

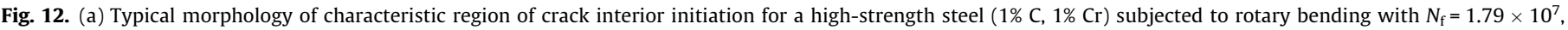
$2 a_{\mathrm{Inc}}=35.3 \mu \mathrm{m}, 2 a_{\mathrm{FGA}}=66.3 \mu \mathrm{m}, 2 a_{\mathrm{FiE}}=235 \mu \mathrm{m}$; (b) schematic showing characteristic region of crack interior initiation and its development to final fracture [43]. 



Fig. 13. (a) The size of FGA and inclusion versus stress amplitude; (b) the $\Delta K$ value for FGA and inclusion versus fatigue life [46].

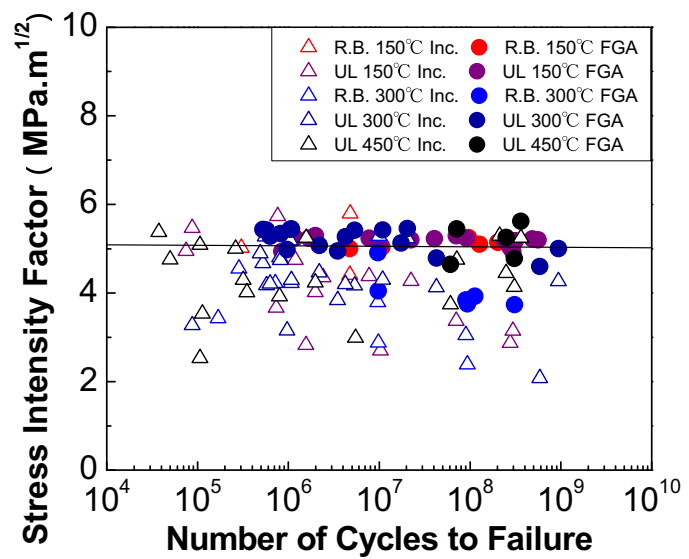

Fig. 14. $\Delta K$ values for FGA and inclusion versus fatigue life [48].

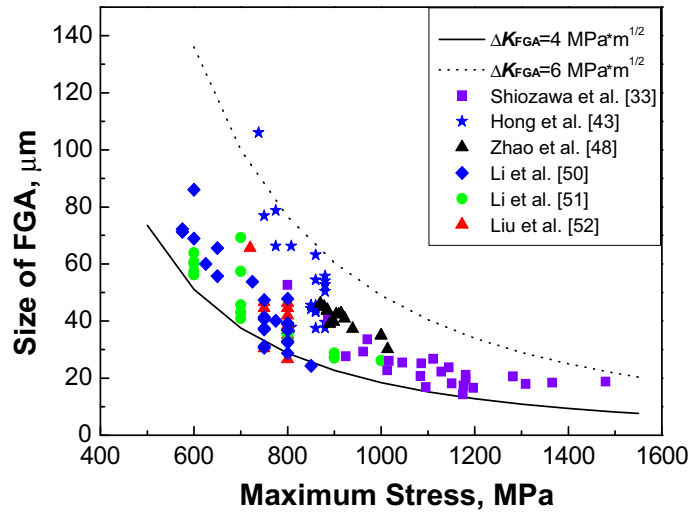

Fig. 15. Variation of FGA size with applied maximum stress, upper bound curve of $\Delta K=6 \mathrm{MPa} \cdot \mathrm{m}^{1 / 2}$ and lower bound curve of $\Delta K=4 \mathrm{MPa} \cdot \mathrm{m}^{1 / 2}[43]$.

reported that the value of $\Delta K$ for FGA was within the range from 4 to $6 \mathrm{MPa} \cdot \mathrm{m}^{1 / 2}$ (Fig. 14). Further, Hong et al. [43] collected a large number of data regarding FGA for high-strength steels (Fig. 15), indicating that the size of FGA was between 15 and $100 \mu \mathrm{m}$ with the trend of large FGA size in low cyclic stress end and small FGA size in high cyclic stress end, i.e. the smaller the cyclic stress, the larger the FGA size and the longer the fatigue life.

The size of FGA and the value of loading stress are fundamentally correlated by the variable of SIF, i.e. Eq. (2). Thus, an upper bound curve of $\Delta K=6 \mathrm{MPa} \cdot \mathrm{m}^{1 / 2}$ and a lower bound curve of $\Delta K=4 \mathrm{MPa} \cdot \mathrm{m}^{1 / 2}$ were plotted in Fig. 15 , showing more than $95 \%$ of datum points were enveloped within these two bounds. This implies that, $\Delta K_{\mathrm{FGA}}$ is a stable variable for crack initiation of VHCF. Therefore, it was definitely concluded [43] that FGA is the charac- teristic region and the corresponding $\Delta K_{\mathrm{FGA}}$ is the characteristic quantity for crack initiation of VHCF, which is intrinsically existed in VHCF process.

An FGA is not doubt a short crack and its growth is restricted by the microstructure of material. From this clue, Zhao et al. $[48,49]$ analyzed the relationship between the plastic zone size ahead of FGA crack tip and the dimension of related microstructure. For a plane strain Mode I crack, the plastic zone size $r_{\mathrm{p}}$ at crack tip [53] is:

$r_{\mathrm{p}}=\frac{(1-2 v)^{2}}{\pi}\left(\frac{\Delta K}{\sigma_{\mathrm{y}}}\right)^{2} \approx \frac{1}{6 \pi}\left(\frac{\Delta K}{\sigma_{\mathrm{y}}}\right)^{2}$

where $v$ is Poisson ratio and $\sigma_{\mathrm{y}}$ is the yield strength of material. On the other hand, the characteristic dimension $l_{\mathrm{m}}$ of material was given as [54]:

$l_{\mathrm{m}}=b\left(\mu / \sigma_{\mathrm{y}}\right)^{2}$

where $b$ is the magnitude of Burgers vector and $\mu$ is the shear modulus of material. It was assumed that at the stage of plastic zone size at FGA crack tip equal to the characteristic dimension of material, the related FGA crack stopped growing or the first transition point shown in Fig. 6 reached. Thus, the following formula was derived [48]:

$\Delta K_{\mathrm{FGA}}=\mu \sqrt{\pi b}=4.342 \mu \sqrt{b}$

Eq. (5) implies that the characteristic quantity of $\Delta K_{\mathrm{FGA}}$ can be simply expressed as a function of the shear modulus and the Burgers vector of material.

For steels, the value of $\Delta K_{\mathrm{FGA}}$ is $5.54 \mathrm{MPa} \cdot \mathrm{m}^{1 / 2}$ by Eq. (5), which is in consistent with various experimental data of $4-6 \mathrm{MPa} \cdot \mathrm{m}^{1 / 2}$ (e.g. $[28,30,33,48,50-52,55,56])$.

For aluminum alloys, the value of $\Delta K_{\mathrm{FGA}}$ is $1.19 \mathrm{MPa} \cdot \mathrm{m}^{1 / 2}$ by Eq. (5), which is in consistent with various experimental data of 1.5$2.8 \mathrm{MPa} \cdot \mathrm{m}^{1 / 2}$ (e.g. [57-61]).

For titanium alloys, the value of $\Delta K_{\mathrm{FGA}}$ is $3.39 \mathrm{MPa} \cdot \mathrm{m}^{1 / 2}$ by Eq. (5), which is in fair agreement with various experimental results of 3.4-4.0 MPa $\cdot \mathrm{m}^{1 / 2}$ (e.g. [61-63]).

For magnesium alloys, the value of $\Delta K_{\mathrm{FGA}}$ is $1.18 \mathrm{MPa} \cdot \mathrm{m}^{1 / 2}$ by Eq. (5), which is in fair agreement with several experimental results of $1.3-1.5 \mathrm{MPa} \cdot \mathrm{m}^{1 / 2}$ (e.g. [58]).

\subsection{Fatigue life and crack growth rate of FGA region}

There have been several results on the fatigue life consumed by the crack initiation phase of VHCF for high-strength steels. The estimations on 2 groups of medium-carbon high-strength steels (with axial cycling at $20 \mathrm{kHz}$ ) by Wang et al. [64] indicated that the life contributed by crack initiation occupied $96.2-99.9 \%$ of the total fatigue life. The estimations on SCM435 steel (with axial cycling at $30-100 \mathrm{~Hz}$ ) by Murakami et al. [65] gave the crack initiation life being $99.8 \%$ of the total fatigue life. Another result on 

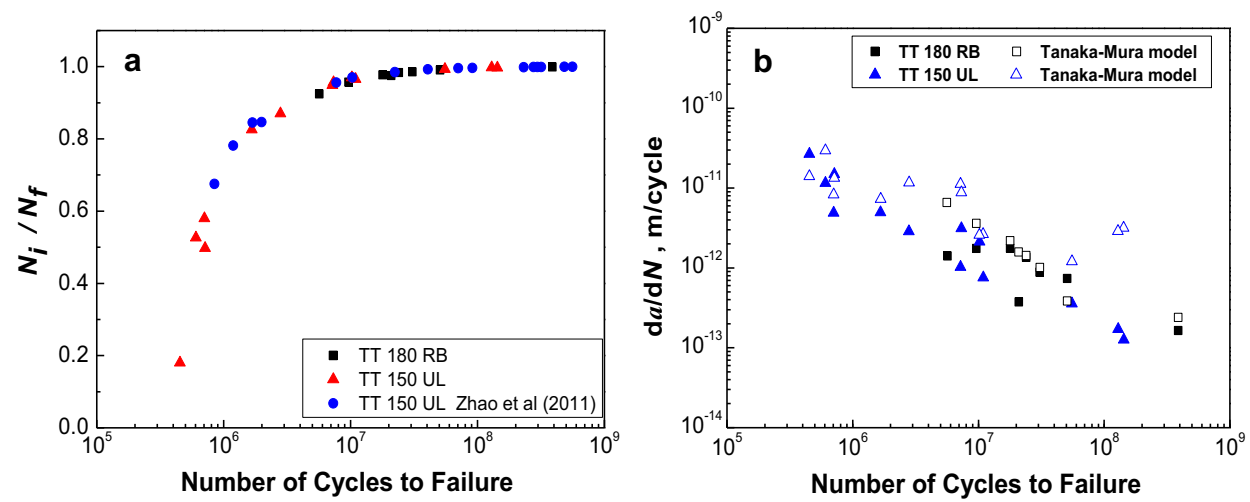


and hollow points indicating model predictions) [43].
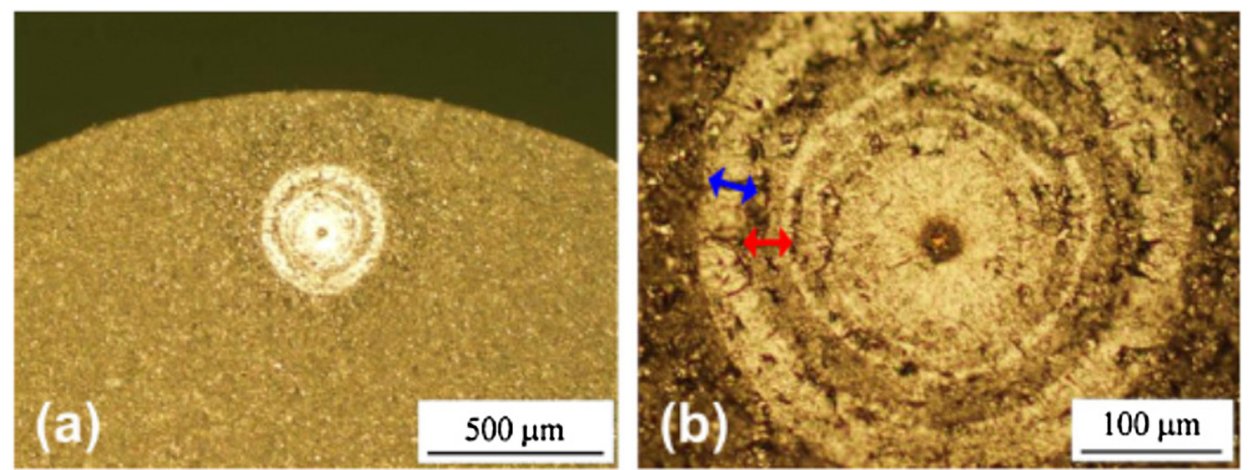

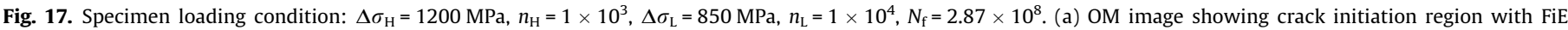
feature; (b) high magnification image showing beach markings and the arrows indicating crack growth increment resulted from repeated two-step loading [72].

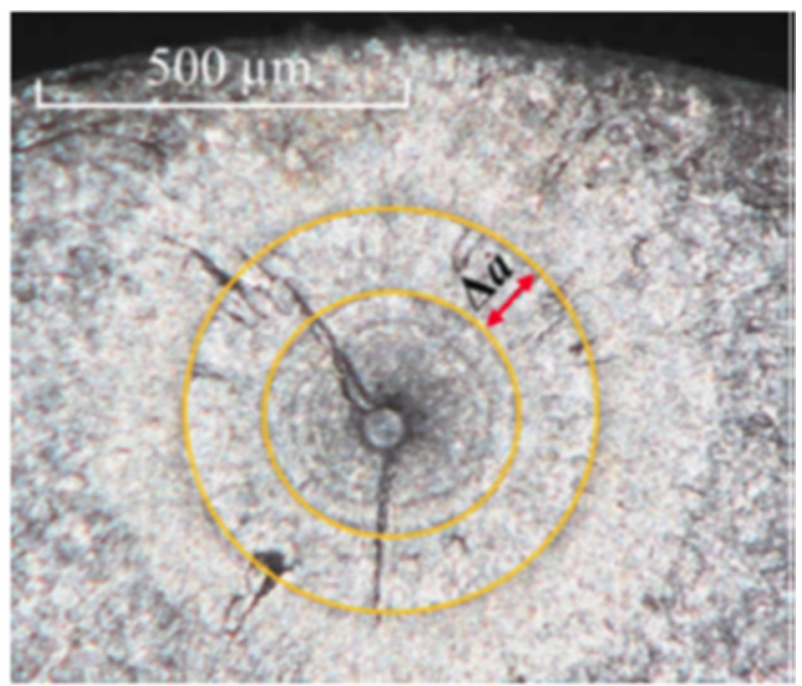

Fig. 18. Arrest markings in FiE region resulted from variable amplitude loading [74].

SUJ2 steel (with rotary bending at $52.5 \mathrm{~Hz}$ ) by Tanaka et al. [66] showed that crack initiation life being $95-99 \%$ of the total fatigue life.

For the crack growth rate in the crack initiation region of VHCF of high-strength steels, Murakami et al. [67] showed the value of $10^{-11}$ to $10^{-12} \mathrm{~m} /$ cyc in the FiE region for SCM435 steel. They noted that the crack growth rate was less than the value of Burgers vector and argued that this type of crack growth did not happen at every loading cycle. Tanaka et al. [66] also provided the estimated value of crack growth rate as $<10^{-12} \mathrm{~m} /$ cyc in the initiation phase of VHCF for SUJ2 steel. They presumed that this type of crack growth was inhomogeneous in its perimeter and the mechanism was not the common dislocation movement.

Recently, Hong et al. [43] further analyzed the fatigue life and the crack growth rate in the crack initiation region of VHCF. Note that $\Delta K_{\mathrm{FGA}}$ corresponds to the threshold value $\Delta K_{\mathrm{th}}$, and the crack will enter the steady growth stage when its length larger than $a_{\mathrm{FGA}}$. Then, it is assumed that Paris relation is applicable for describing the relationship between $\mathrm{d} a / \mathrm{d} N$ and $\Delta K$ when the crack length beyond $a_{\mathrm{FGA}}$, which is:

$\frac{\mathrm{d} a}{\mathrm{~d} N}=A \Delta K^{m}$

where $A$ and $m$ are material parameters. The fatigue life from $a_{\mathrm{FGA}}$ to $a_{\mathrm{FiE}}\left(N_{1}\right)$ and that from $a_{\mathrm{FiE}}$ to final crack length $a_{\mathrm{c}}\left(N_{2}\right)$ can be calculated by the integral of Eq. (6). Thus, the fatigue life consumed by FGA, i.e. the crack initiation life $N_{\mathrm{i}}$ is:

$N_{\mathrm{i}}=N_{\mathrm{f}}-N_{1}-N_{2}$

Based on this, the calculation result (Fig. 16a) on a GCr15 steel (similar to SUJ2) shows that the normalized crack initiation life $N_{\mathrm{i}} / N_{\mathrm{f}}$ increases with the increasing of fatigue life [43]. When fatigue life beyond $10^{7}$ cycles, the life consumed by the crack initiation region FGA is larger than $95 \%$; when $N_{\mathrm{f}} \geq 5 \times 10^{7}, N_{\mathrm{i}} / N_{\mathrm{f}}$ is larger than $99 \%$. For crack growth rate in FGA region, Fig. $16 \mathrm{~b}$ shows that $\mathrm{d} a / \mathrm{d} N$ decreases with the increasing of fatigue life [43]. When $N_{\mathrm{f}}$ is between $10^{7}$ and $4 \times 10^{8}$ cycles, the value of $\mathrm{d} a / \mathrm{d} N$ is between 
$10^{-12}$ and $10^{-13} \mathrm{~m} / \mathrm{cyc}$. A model was developed [43] based on Tanaka-Mura method [68], and the simulations on crack growth rate in FGA region are in agreement with experimental estimations (Fig. 16b).

More recently, the estimations from a series of experiments on a Ti-6Al-4V alloy showed that the value of $N_{\mathrm{i}} / N_{\mathrm{f}}$ was $96.1-99.9 \%$ and the value of $\mathrm{d} a / \mathrm{d} N$ was $10^{-11}$ to $10^{-13} \mathrm{~m} /$ cyc at the fatigue life between $10^{7}$ and $10^{9}$ cycles [69].

\subsection{Experimental measurements on crack growth rate in initiation region}

In recent years, researchers have made special attempts to the experimental measurement on crack growth rate in initiation region. Stanzl-Tschegg et al. [70] used tubular type specimens with pre-notch and tested via ultrasonic axial cycling at $19 \mathrm{kHz}$ and $R=0.05$ and 0.5 . Based on the comparison of the fractographic features between the specimen tested in vacuum and that contained FiE morphology, they inferred that the value of $\mathrm{d} a / \mathrm{d} N$ in FGA was $10^{-12} \mathrm{~m} /$ cyc and the value in the FiE region outside FGA was $10^{-11} \mathrm{~m} /$ cyc; whereas for the region outside FiE, the value was $10^{-9} \mathrm{~m} /$ cyc.

Ogawa et al. [71,72] adopted the method of "two-step" and "repeated two-step" tests via ultrasonic axial cycling $(20 \mathrm{kHz}, R=-1)$ to detect the crack trace during its initiation for SUJ2 steel. Fig. 17 is their result via repeated two-step test, showing beach marks in the FiE region, from which they obtained the value of $\mathrm{d} a / \mathrm{dN}$ as $10^{-7}$ to $10^{-9} \mathrm{~m} /$ cyc. For the crack growth in FGA region, their estimated result via "two-step" test gave the $\mathrm{d} a / \mathrm{d} N$ value of $10^{-13}$ to $10^{-14} \mathrm{~m} /$ cyc.

Sander et al. $[73,74]$ adopted the method of variable amplitude loading to detect the crack growth trace at its initiation on 34 CrNiMo6 steel via ultrasonic axial cycling $(21 \mathrm{kHz}, R=-1)$. Fig. 18 shows the observed arrest marks in the FiE area, from which they obtained the $\mathrm{d} a / \mathrm{d} N$ value of $3 \times 10^{-11}$ to $2 \times 10^{-12} \mathrm{~m} / \mathrm{cyc}$ in the FiE region outside FGA.

The work by Ogawa et al. $[71,72]$ with repeated two-step testing and the work by Sander et al. $[73,74]$ with variable amplitude loading are effective to identify the crack growth fronts at different steps during the initiation process, and thus enables the measurement of crack growth rate in the initiation phase. However, these measurements are in the FiE area outside FGA. Up to date, there is no a result regarding the direct observation and measurement of crack growth on the initiation region of FGA.

\section{The formation mechanism and the model of crack initiation region}

In the previous sections of this overview, it has been intensively described that in VHCF regime, crack initiation always from the interior of material (specimen). For high-strength steels, the initiation region presents the features of FiE and FGA. Although the size of FGA is just tens of microns, as the characteristic region of crack initiation for VHCF, it consumes more than 95\% of total fatigue life $[43,66]$. Therefore, it is particularly important to reveal the formation mechanism of FGA and thus to understand the unique behavior of VHCF and the related fatigue life prediction.

\subsection{Previous models to interpret FGA formation mechanism}

In the past two decades, several researchers proposed some models to explain the formation mechanism of crack initiation region, which are summarized in the follows.

\subsubsection{Hydrogen assisted crack growth to form ODA (i.e. FGA)}

Murakami et al. $[65,67,75]$ observed a dark area, by optical microscopy and atomic microscopy, surrounding the inclusion as crack origin in the crack initiation region of VHCF, and called this ODA i.e. FGA. Based on the examinations of hydrogen trapped at the interface of inclusions [76,77], they presumed that the formation of FGA was due to the effect of hydrogen trapped by the nonmetallic inclusion superimposed on the fatigue stress. Thus, the existence of hydrogen trapped by an inclusion induced the discrete crack growth at a very slow rate during crack initiation and produced a rough fracture surface. When the size of FGA reached the critical value, crack steady growth occurred without the assistance of hydrogen. A recent investigation [78] reported that hydrogen-charged specimens were more prone to form FGA feature even in the short life region of $10^{4}$ and $10^{5}$ cycles.

\subsubsection{Decohesion of spherical carbides to form GBF (i.e. FGA)}

Shiozawa et al. $[29,32,33,47]$ used the techniques of 3-D scanning electron microscopy (SEM), scanning probe microscopy (SPM) and electron probe microanalysis (EPMA) to show that the surface roughness in FGA region corresponded to the size of spherical carbides, and FGA region contained relatively rich carbon content. Then they proposed that the formation of FGA was due to the decohesions of spherical carbides from the matrix to cause crack initiation in the vicinity of an inclusion. The coalesced crack was along the boundary between spherical carbides and the matrix with the generated roughness to form an FGA region. After the formation of a certain size for FGA, the crack propagation was independent of the spherical carbide decohesion.

\subsubsection{Formation and debonding of fine granular layer to form FGA}

Sakai [27] considered that a number of fine sub-grains with different crystal orientations generated within a thin layer around the non-metallic inclusion to be crack origin due to a large number of loading cycles prior to crack initiation. The detailed observations on high-strength steels by Sakai and coauthors $[79,80]$ showed that fine grain microstructure was only at one side of the mated fracture surfaces, i.e. one side of fracture surface was with fine grain microstructure and the other side was without. Then they concluded: FGA was produced by the debonding of the fine granular layer and the matrix to form the rough morphology, and the fine granular layer was generated (before crack initiation) by the intensive polygonization in the vicinity of an inclusion during the long sequence of cyclic loading. When a penny-shape crack of FGA was formed around the inclusion, the size of FGA was terminated and the crack growth tended to Paris crack regime. The recent investigations by Chai et al. [81,82] believed that the localized plastic deformation would promote the formation of FGA. Note that this explanation regarded the formation of FGA was prior to crack initiation and the FGA crack was along the boundary between the fine sub-grain layer and the matrix.

An investigation by Grad et al. [83] reported that an average grain size of about $70 \mathrm{~nm}$ was observed in the FGA layer for a high-strength steel and proposed the FGA formation mechanism of "local grain refinement at the crack tip". In fact, this model is very similar to the model of "formation and debonding of fine granular layer" by Sakai [27]. It should be noticed that the model by Sakai [27] and later by Grad et al. [83] stated that the fine grain layer is produced before crack formation or at the head of crack tip.

\subsubsection{Vortical plastic flow to produce thin nanostructure layer}

The above three models mainly focused on the situation of VHCF for high-strength steels. The model proposed by Shanyavskiy [84] tried to explain the cases involving other high-strength alloys. It was described "Vortical plastic flows ... are creative of a thin nanostructure layer ...", and "The nanoscopic grains experience 

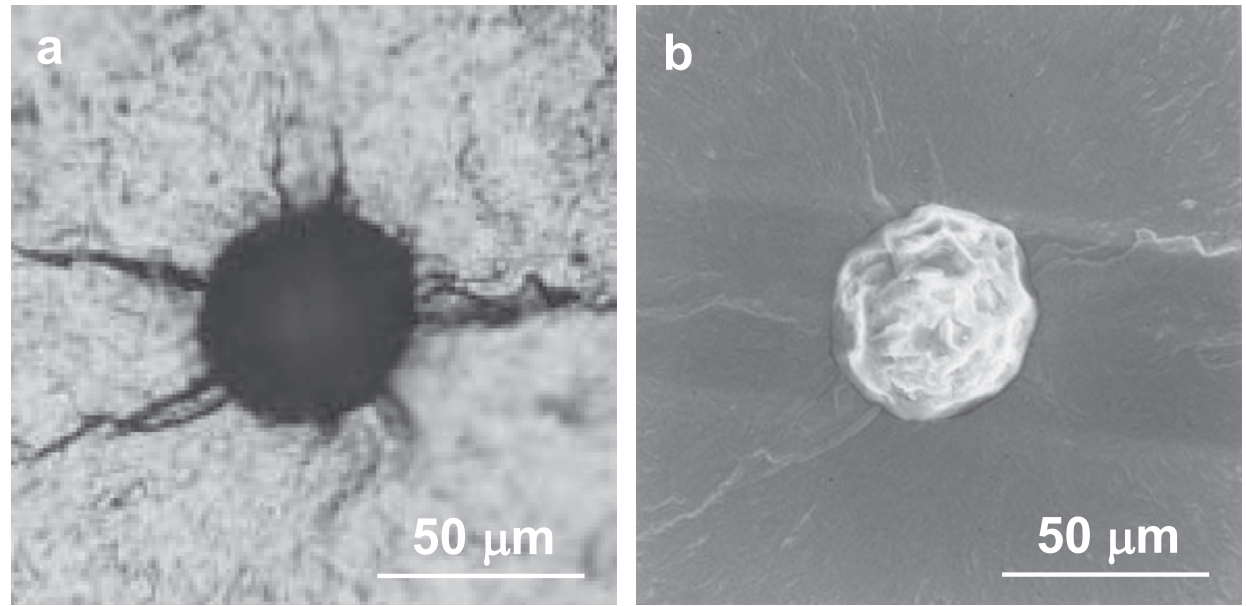

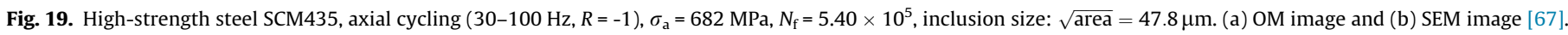
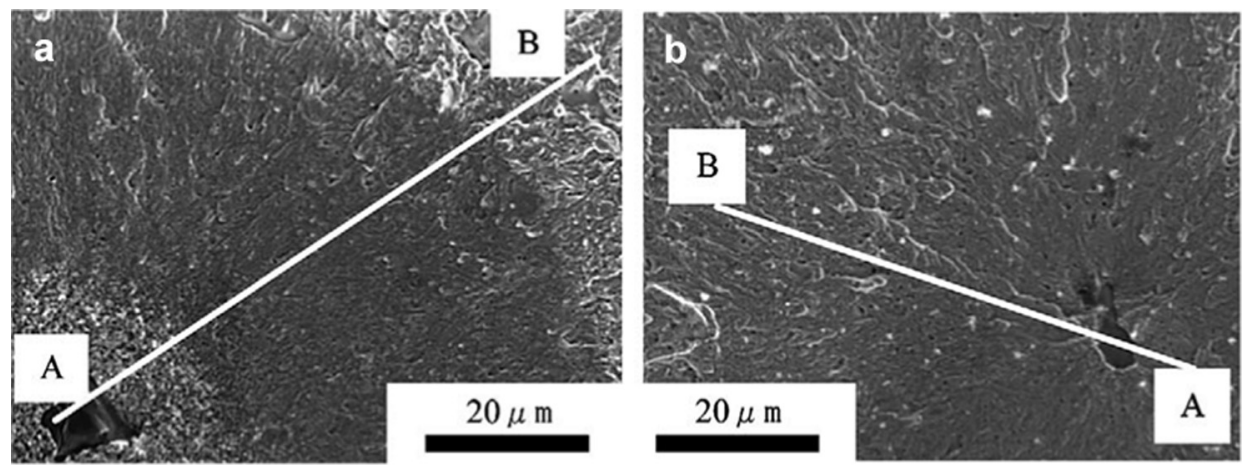


morphology for a shot-peened SUJ2 steel subjected to rotary bending with $\sigma_{\mathrm{a}}=1600 \mathrm{MPa}, N_{\mathrm{f}}=3.7 \times 10^{5}$ [33]. (Line AB is the location for roughness measurement.)
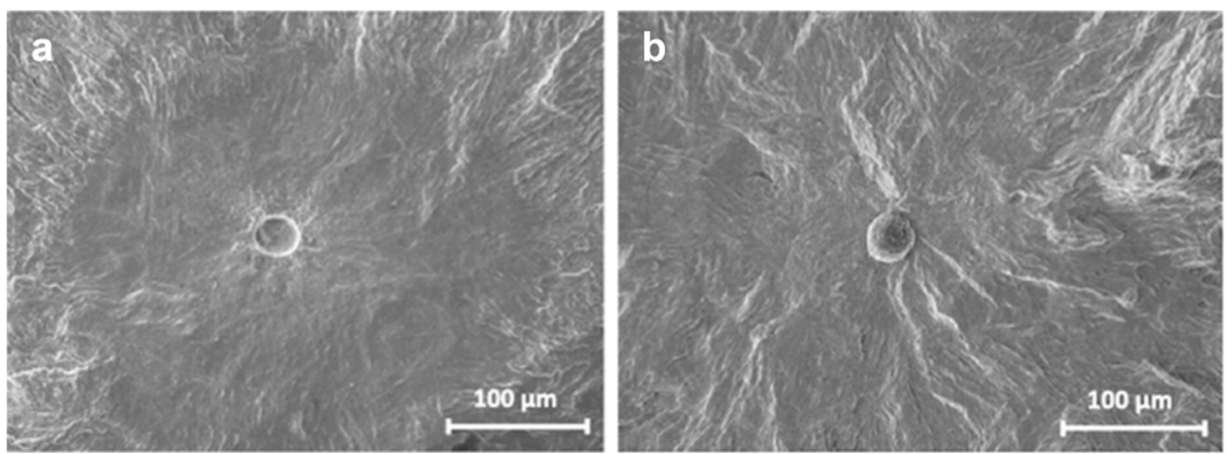

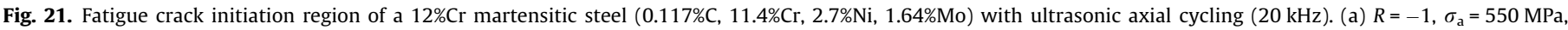
$N_{\mathrm{f}}=4.66 \times 10^{7}$; (b) $R=0.5, \sigma_{\mathrm{a}}=250 \mathrm{MPa}, N_{\mathrm{f}}=4.87 \times 10^{7}[86]$.

rotation in each compression/tension half-cycle; thereby the grainboundary strength (cohesion) diminishes to allow grains partition and to form the free surface of the particles in the FGA zone" [84]. This is an imaginative model, although the physical detail of this model needs to be verified. This model presumed that nanoscopic particle pre-existed in the vicinity of the inclusions and the nanograins generated also before the related crack formation, which shared the viewpoint of the model by Sakai [27].

\subsubsection{Cold welding induced grain refinement to form RA for titanium alloys}

Oguma et al. [85] noticed that the fine granular region existed only on the fracture surfaces in vacuum environment, and the fine concave-convex feature on fracture surfaces in high-strength steels and aluminum alloys, which was in relation with the refinement of microstructure. Then they proposed for titanium alloys that the direct metal-metal contacts may occur during the ultralong cycling process, causing "cold-welding" at the contact surfaces. During this process, microstructure refinement may occur near crack surfaces, leading to the formation of RA. This is also an imaginative model but without the evidence to support the existence of coldwelding process.

\subsection{In-explainable cases by previous models}

The validity of a model lies in its ability of explaining the results obtained from different conditions. The mechanisms and the 
(a)

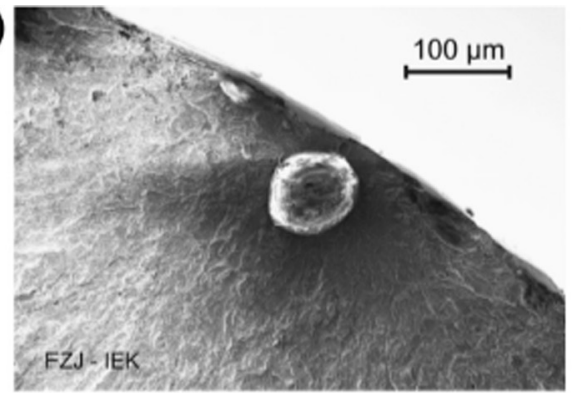

(c)

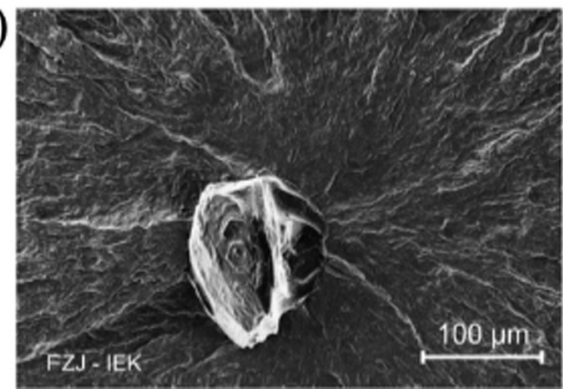

(b)

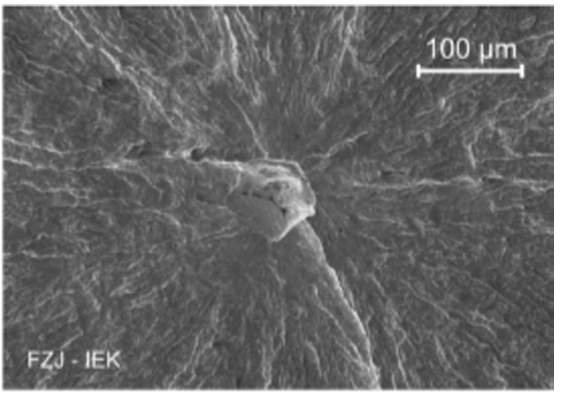

(d)

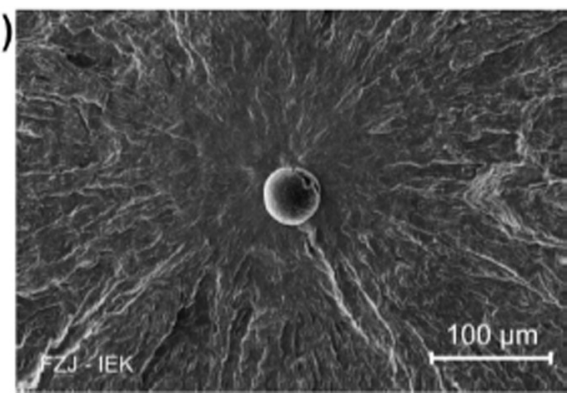

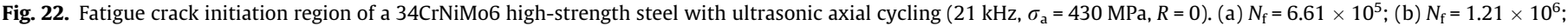
(c) $N_{\mathrm{f}}=2.24 \times 10^{6}$; (d) $N_{\mathrm{f}}=2.57 \times 10^{8}$ [73] .
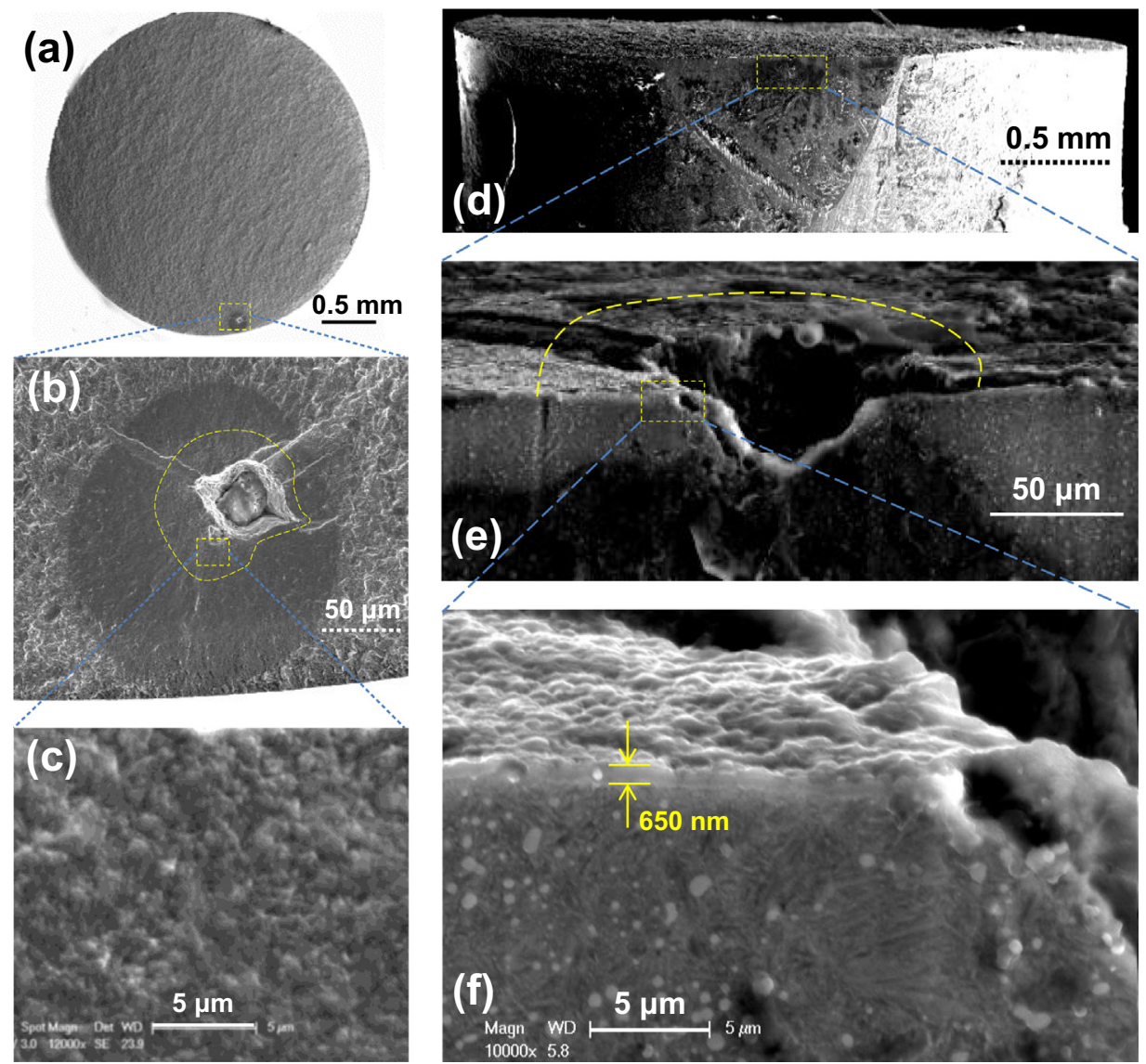

Fig. 23. SEM images of specimen failed at $N_{\mathrm{f}}=2.40 \times 10^{7}$ with $\sigma_{\max }=775 \mathrm{MPa}$. (a)-(c) Top view of crack initiation region; (d)-(f) lateral view of FGA region [87].

related models mentioned above can only explain certain results of FGA formation. These models encountered difficulties in the explanation of general cases with different loading conditions or different loading cycles. The following examples are some inexplainable cases.
Example 1. At the same time the model of "hydrogen assisted crack growth to form ODA" was proposed, Murakami et al. [67] gave the VHCF results of SCM435 high-strength steel with axial cycling $(30-100 \mathrm{~Hz}, R=-1)$, showing that ODA (i.e. FGA) size increased with fatigue failure cycles and that for some specimens 

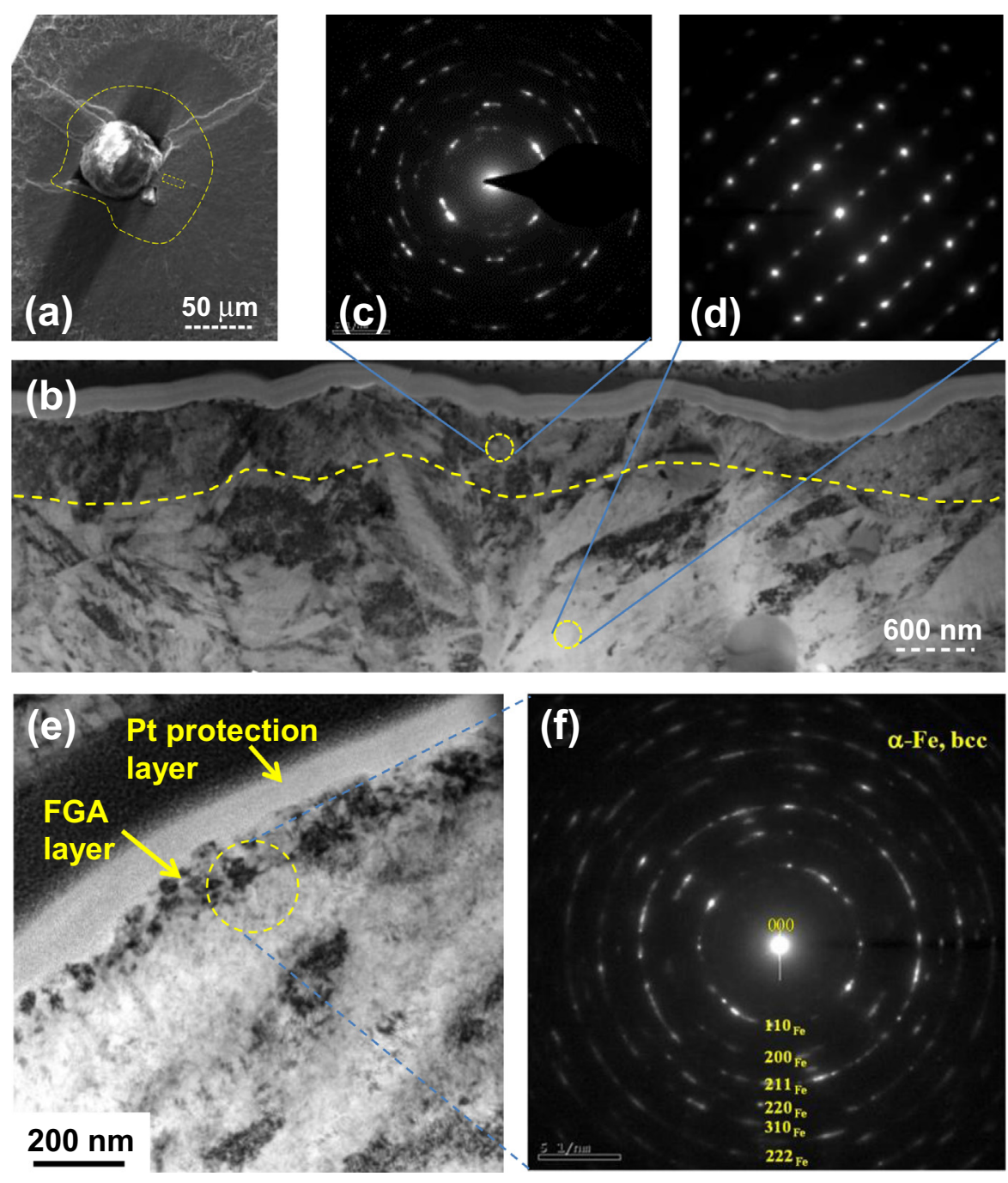



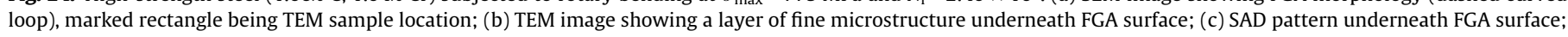

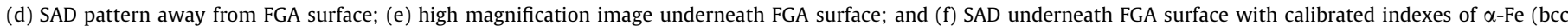
lattice) [87].

failed at HCF regime, the crack initiation region presented FiE feature but without ODA or FGA, e.g. Fig. 19. This result (Fig. 19) cannot be explained by the previous models.

Example 2. At the same time the model of "decohesion of spherical carbides to form GBF" was proposed, Shiozawa et al. [32,33] provided the observations on SUJ2 high-strength steel with rotary bending, showing the feature of FGA within FiE in the crack initiation region for the specimens with higher failure cycles (e.g. Fig. 20a), whereas for the specimen with relatively lower failure cycles, interior crack initiation at inclusion presented FiE but without FGA morphology (Fig. 20b). This result cannot be explained by the previous models.

Example 3. In the investigations on $12 \% \mathrm{Cr}$ martensitic steel with ultrasonic axial cycling at different stress ratios $(R=-1,0.1,0.5$, 0.7 ), Kovacs et al. [86] observed that for the case of $R=-1$, crack initiated from interior inclusion and presented the feature of FiE containing FGA (e.g. Fig. 21a), whereas for the cases with positive stress ratios, the VHCF crack initiation was also from interior inclusion with the feature of FiE but without FGA (e.g. Fig. 21b). They used the method of focused ion beam (FIB) to section the sample from crack initiation region. The SEM observations showed that for $R=-1$, there was a nanocrystal layer of about $3 \mu \mathrm{m}$ thick in crack initiation region, whereas for $R=0.1$, no nanocrystal layer was observed in crack initiation region and the microstructure was original martensite feature. The morphology difference between the case of $R=-1$ and the case of positive stress ratios cannot be explained by the above mentioned models.

Example 4. The investigation by Sander et al. [73] with ultrasonic axial cycling ( $21 \mathrm{kHz}, R=-1$ and 0 ) obtained the effects of inclusion size and shape on the VHCF behavior of 34CrNiMo6 highstrength steel. Their observations showed that for all cases of crack initiation region, the feature of FiE prevailed but all without FGA morphology. Fig. 22 shows the results of four cases with failure cycles from $6.61 \times 10^{5}$ to $2.57 \times 10^{8}$; all are without FGA morphology. These results cannot be explained by above described models.

The above four examples can be summarized as three categories: (1) for the same material and the same loading type (axial cycling or rotary bending), the crack initiation feature for the specimens with longer failure cycles being FiE containing FGA, whereas 
the feature for the specimens with shorter failure cycles $\left(\sim 10^{5}\right.$ failure cycles) being FiE without FGA (Examples 1 and 2); (2) for the same material and the same loading type, the crack initiation feature for the specimens with stress ratio $R<0$ being FiE containing FGA, whereas the feature for the specimen with $R>0$ being FiE but without FGA (Example 3); (3) for medium-carbon steels failed in HCF and VHCF regimes, crack initiation from interior inclusion presenting FiE but without FGA feature (Example 4). The previous models cannot explain these experimental observations. Therefore it is necessary to develop a new model to interpret the formation mechanism of crack initiation region of VHCF.

\section{The new model of numerous cyclic pressing to explain the formation mechanism of FGA}

In order to clearly reveal the microscopic nature of FGA and to further identify the formation mechanism of this characteristic region, Hong et al. [87] carried out a series of investigations and reported new results with respect to this aspect.

\subsection{The nature of FGA}

Hong et al. [87] used a high-strength steel with the main composition (wt.\%) of $1.06 \mathrm{C}, 1.04 \mathrm{Cr}, 0.88 \mathrm{Mn}, 0.34 \mathrm{Si}$ and Fe balance to perform VHCF test with rotary bending $(52.5 \mathrm{~Hz}, R=-1)$.
The SEM images of Fig. 23 [87] show the morphology of an FGA region for the specimen failed at $N_{\mathrm{f}}=2.40 \times 10^{7}$ with $\sigma_{\max }=775$ MPa. From the top view (Fig. 23a-c), it is seen that the FiE (equivalent diameter $160 \mu \mathrm{m}$ ) contains an FGA (equivalent diameter $79 \mu \mathrm{m}$ ) originating from an inclusion, and the FGA is of rough surface under a high magnification (Fig. 23c). From the lateral view (Fig. 23d-f), it is seen that the region of FGA is a thin layer of rough morphology with the average thickness of $650 \mathrm{~nm}$ (Fig. 23f).

For the identification of the microscopic nature of this thin layer, a profile sample cut from the counterpart of Fig. 23b via FIB was examined with TEM associated with selected area electron diffraction (SAD) and the results are shown in Fig. 24 [87]. The TEM image of Fig. 24b shows a narrow band of about $500-800 \mathrm{~nm}$ in width underneath the FGA region with fine microstructure. The SAD pattern underneath FGA surface (Fig. 24c) is discontinuous diffraction circles, suggesting several grains existing (by the diffraction principle [88]) within the diffraction diameter of $200 \mathrm{~nm}$, whereas away from the narrow band, the SAD (Fig. 24d) is a pattern of isolated spots resulted from a single grain. The calibration of SAD pattern in the FGA layer matches the standard diffraction of iron (Fig. 24f). From high magnification images such as Fig. 24e, an average of equivalent grain diameter of $48 \mathrm{~nm}$ was obtained.

Further, the same location of both sides of crack initiation region was examined [87] on a specimen failed at $N_{\mathrm{f}}=9.64 \times 10^{6}$ with $\sigma_{\max }=850 \mathrm{MPa}$ (Fig. 25). The FIB sample is such located that
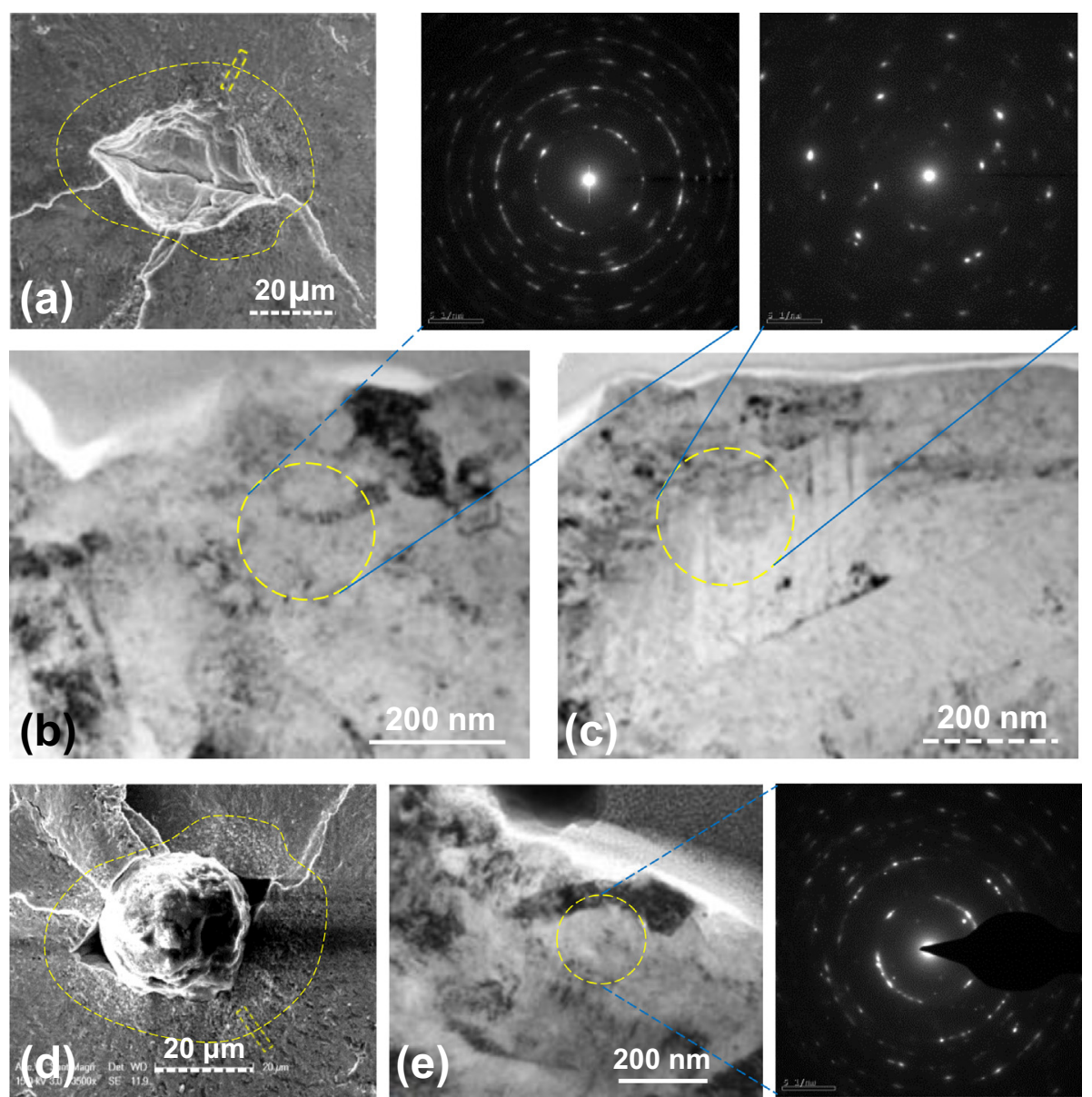

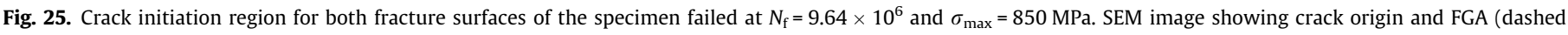

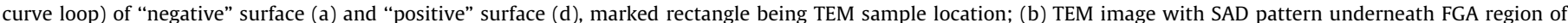

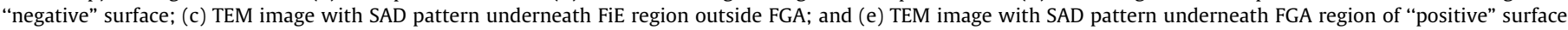
[87]. 



Fig. 26. Schematic of Numerous Cyclic Pressing (NCP) model [87].
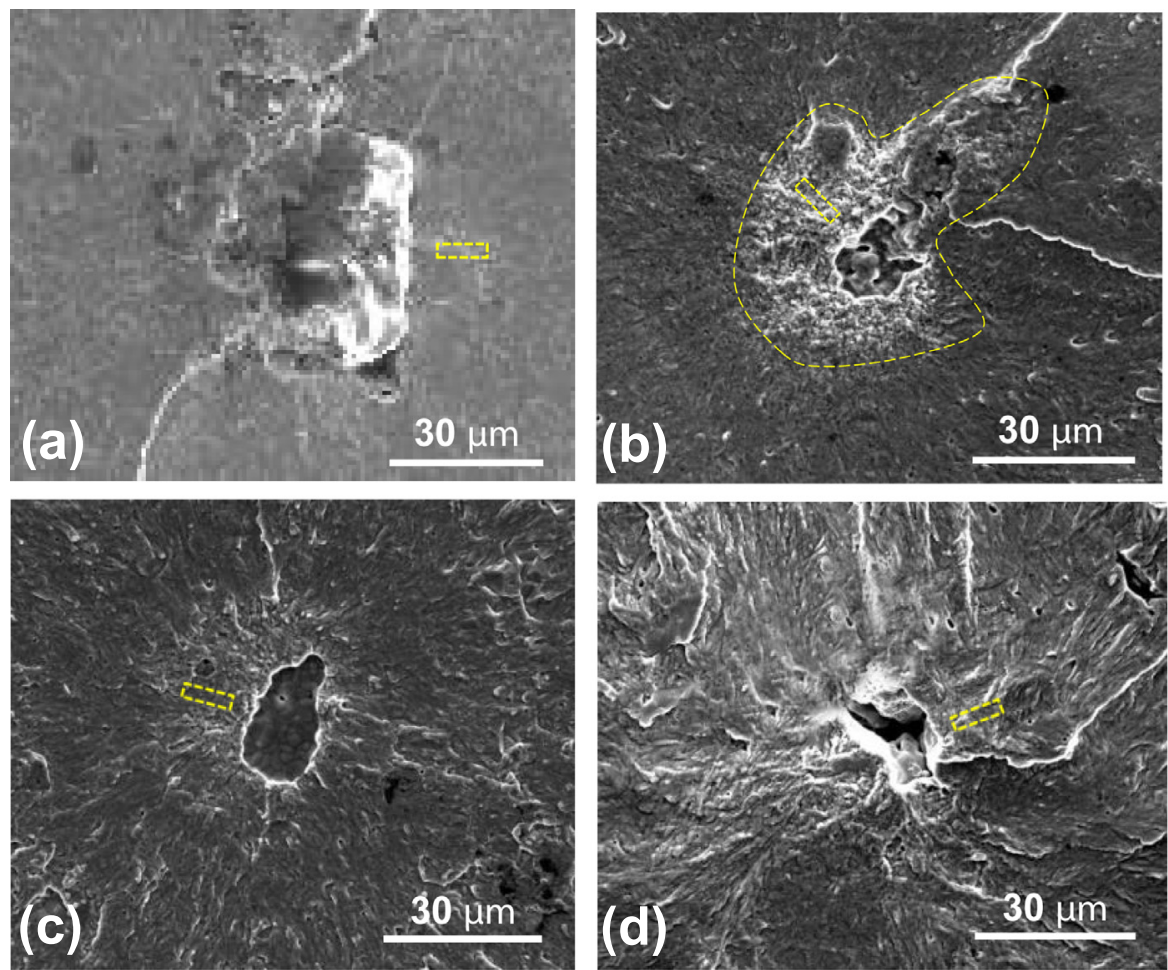

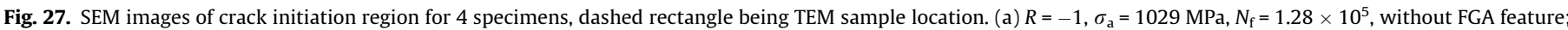

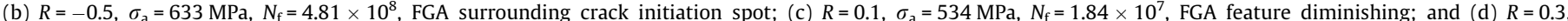
$\sigma_{\mathrm{a}}=422 \mathrm{MPa}, N_{\mathrm{f}}=9.76 \times 10^{7}, \mathrm{FGA}$ feature diminishing [87]. 

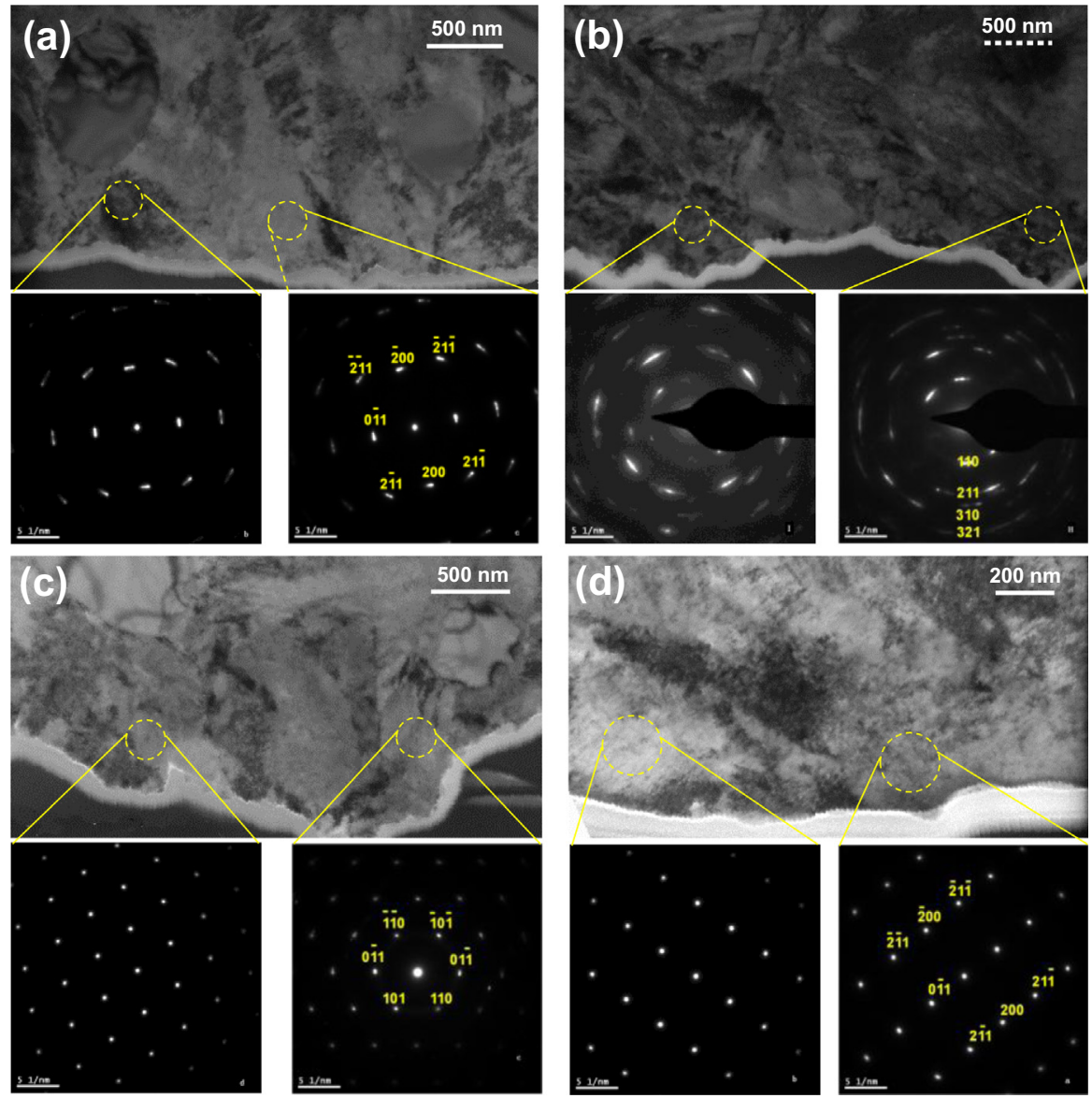

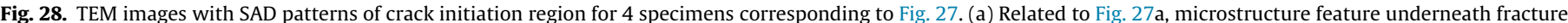

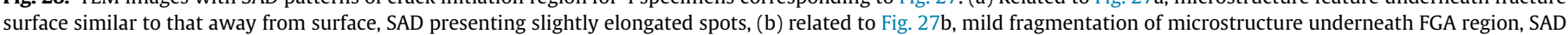

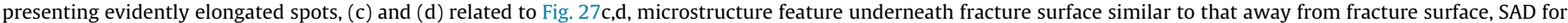
each case presenting isolated spots [87].

it contains half of the FGA region and another half of the FiE region outside FGA. The TEM observations showed that nanograins within the FGA layer (Fig. 25b), whereas coarse grains in the FiE region outside FGA (Fig. 25c). For the opposite side of the fracture surface, the observations give very similar results as those of its counterpart with Fig. 25e as an example showing nanograins in the FGA layer. This result is the first time to reveal that both sides of FGA region are nanograin layers.

\subsection{The formation mechanism of FGA}

Based on the revealed microscopic nature of crack initiation region, Hong et al. [87] proposed a model of Numerous Cyclic Pressing (NCP) to explain the formation mechanism of FGA, which is schematically shown in Fig. 26. After an initial number of loading cycles, the evolution due to localized plastic deformation in the vicinity of an activated inclusion may induce fatigue crack initiation (Fig. 26a). The crack wake of the originated crack is subjected to the repeated pressing caused by the cyclic loading, which is associated with the action of crack closure [89] and the release of residual stress [90]. Thus the microstructure of the crack surface layer will be fragmented and become nanograins due to localized intensively plastic deformation (Fig. 26b). This process gradually continues and the previous crack surfaces become a thin layer of nanograins with rough morphology after millions of loading cycles (Fig. 26c). At the transient condition from crack initiation to steady growth, the NCP process is terminated and the critical size of FGA is attained (Fig. 26d).

The critical size of FGA is further analyzed. Based on Eq. (2), the transient condition was derived as

$a_{\mathrm{FGA}}=Y^{\prime}\left(\frac{\Delta K_{\mathrm{FGA}}}{\sigma_{\max }}\right)^{2}$

where $a_{\mathrm{FGA}}$ is FGA size, $\Delta K_{\mathrm{FGA}}$ is the related stress intensity factor range for FGA, $\sigma_{\max }$ is applied maximum stress and $Y^{\prime}$ is crack shape parameter that takes the same value as Eq. (2) of $4 / \pi$. In relation to the assumption that the critical state for the termination of FGA is the plastic zone size of an originated crack equal to the characteristic microstructure dimension (referred to Eq. (5)), thus it gives

$a_{\mathrm{FGA}}=Y b\left(\frac{\mu}{\sigma_{\max }}\right)^{2}$

with $Y$ being $6 \pi Y^{\prime}=24$ for the present case. Eq. (9) implies that for a given material, the critical size of FGA is inversely proportional to the square of the applied maximum stress.

It is worth noting that the NCP process may act as a new method of severe plastic deformation to fabricate nanostructured metals and alloys as the similar ones [91,92]. Thus, the NCP model also provides a new concept for creating new approaches to produce metallic thin-film with nano-sized microstructure. 

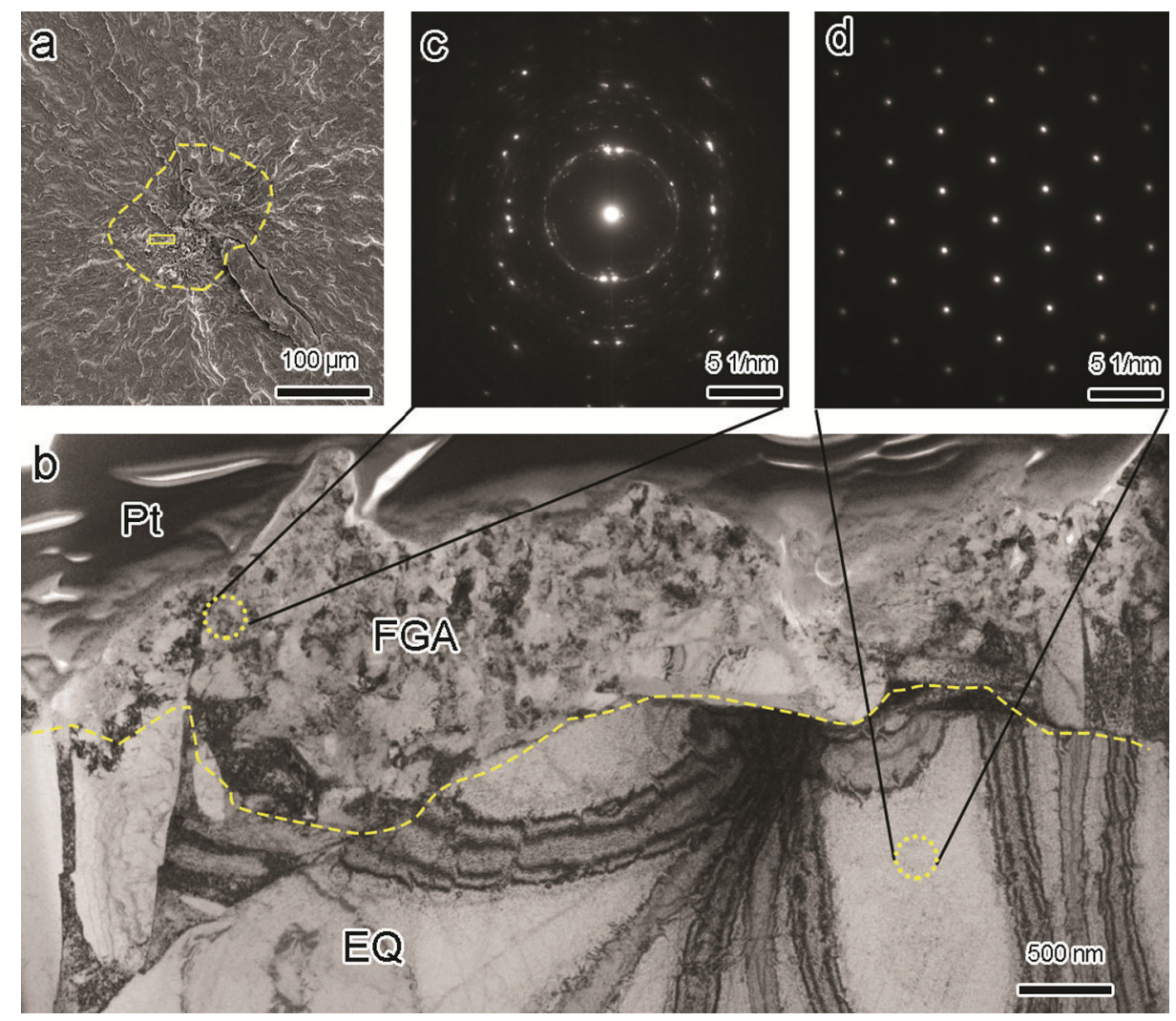

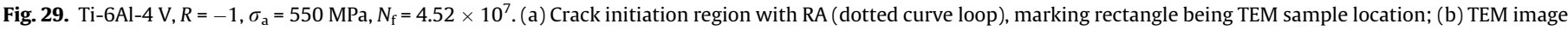
showing nanograin (NG) layer and equiaxed grain (EG) layer; (c) SAD pattern underneath RA surface; and (d) SAD pattern away from RA surface [69].

\section{Verification of proposed NCP model}

The proposed NCP model suggested that the formation of FGA nanograin layer requires two basic conditions: (1) the existence of compressive stress between originated crack surfaces to result in the contacting and pressing between the crack surfaces, and (2) sufficient number of loading cycles to provide enough cycles of repeated contacting and pressing.

Thus, one may come up with two predictions from the NCP model: (1) the tendency of FGA nanograin layer formation is inversely proportional to the applied stress ratio, i.e. high possibility for negative stress ratio condition and low possibility for positive stress ratio condition, because the state of positive stress ratio reduces the possibility of the contacting and pressing between crack surfaces, and (2) even for a negative stress ratio condition, if the number of loading cycles is relatively low, the tendency of FGA nanograin layer formation is low, because the low number of loading cycles results in an insufficient number of repeated contacting and pressing between crack surfaces.

\subsection{Verification of the two predictions}

For the purpose of verifying the two predictions, a specially designed experiment was performed [87], for which fatigue tests on a GCr15 (similar to SUJ2) high-strength steel were conducted via ultrasonic axial cycling with the frequency of $20 \mathrm{kHz}$ and the stress ratio was at $R=-1,-0.5,0.1$ and 0.3 , respectively.

For the case of $R=-1$ and failed in VHCF regime, fatigue crack initiated from the interior of specimen with the morphology of FiE containing FGA. The examinations by TEM with SAD indicated that a layer of nanograins appeared underneath the FGA surface, whereas in the location away from the FGA surface, coarse microstructure remained. Such observations confirmed that for the case of $R=-1$ failed in VHCF regime, the FGA region is a layer of nanograins.

For the case of $R=-1$ but failed at a relatively small number of loading cycles (the magnitude of $10^{5}$ ), the fractography shows crack initiated from the interior of specimen but the region of crack initiation was almost without FGA morphology (Fig. 27a). Fig. 28a shows the related microstructure feature of the FIB sample, and the associated SAD patterns detected from the location underneath the fracture surface of crack initiation region show a kind of slightly elongated spots, which is a reflection of texture feature (by the diffraction principle [88]). The evidence of texture-like microstructure in the surface layer of originated crack wake is surprising, which suggests that just a couple of grains (no many) exist with very close crystallographic orientation within the diffraction area. This evidence verifies the second prediction that for the case of relatively low cyclic numbers at negative stress ratio, the formation of nanograins in the wake of originated crack is incomplete.

Fig. 27b shows an example subjected to $R=-0.5$ failed in VHCF regime, indicating that fatigue crack initiated from the interior of specimen and the region of crack initiation was FGA surrounding the crack origin. Fig. 28b is the related TEM image from the crack initiation region showing a layer of fine grains underneath the FGA surface, and the associated SAD patterns detected from the location underneath fracture surface in the crack initiation region present obviously elongated spots, which is likely a layer of nanograins with close crystallographic orientations. The SAD circles for this specimen are not as continuous as those subjected to $R=-1$ failed in VHCF regime, but the spots (Fig. 28b) are much elongated than the case of Fig. 28a, suggesting that the number of grains within the diffraction area for the case of $R=-0.5$ failed in VHCF 

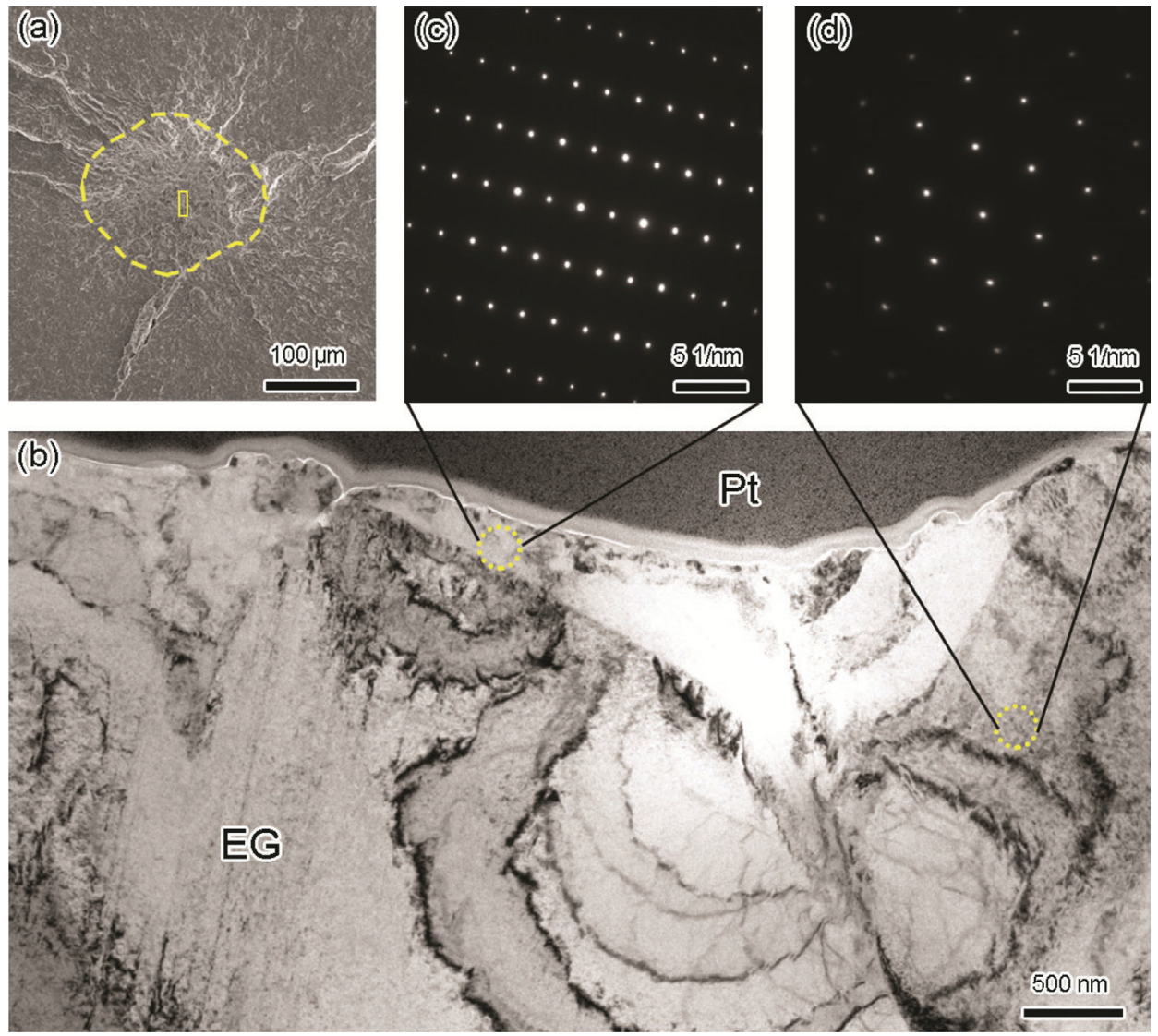

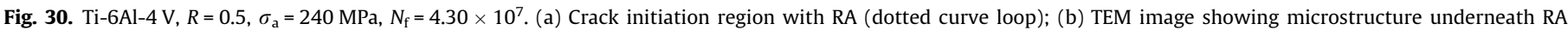
surface; (c) SAD pattern underneath RA surface; and (d) SAD pattern away from RA surface [69].

regime is less than that for the case of $R=-1$ failed in VHCF regime but the number of grains is more than that for the case of $R=-1$ failed at a relatively small number of loading cycles.

The SEM images of Fig. 27c, d show the crack initiation region for the specimens of $R=0.1$ and 0.3 , respectively. They all failed in VHCF regime with crack initiation from the interior of specimen, and the crack initiation region was almost without FGA morphology. The related TEM images with SAD patterns of Fig. 28c, d show that for these two cases, only a single grain presents in the diffraction area at the wake of originated crack, i.e. coarse grain remains in crack initiation region. This gives distinct evidence to verify the first prediction that for positive stress ratio conditions, the formation of nanograins in the wake of originated crack is less possible due to the less crack closure effect and the less contacting action between two crack surfaces.

\subsection{Further results in support of NCP model}

More recently, a couple of new results further validated the NCP model. The observations on a medium-carbon steel via rotary bending by Jiang et al. [93] reported that for the specimen failed in VHCF regime, crack initiated from the interior of specimen with FiE containing FGA, and the FGA region was a layer of nanograins. This result indicated that the NCP model is valid for different type of steels including medium-carbon structural steels.

Another very recent result was on a Ti-6Al-4V alloy subjected to ultrasonic axial cycling at different stress ratios. Su et al. [69] revealed that, for the specimen tested at $R=-1$ and failed in VHCF regime, crack initiated from the interior of specimen with the initiation region of RA feature, and the RA region was a layer of nano- grains with the width of $800-1500 \mathrm{~nm}$ and the average grain diameter of $105 \mathrm{~nm}$ (Fig. 29). For the specimen tested at $R=0.5$ and failed in VHCF regime, crack also initiated from the interior of specimen with the initiation region of RA feature, but the RA region remained original coarse microstructure feature (Fig. 30), i.e. no evidence of grain refinement in the crack initiation region for the case tested at positive stress ratio. This result indicates that the NCP model is valid not only for high-strength steels but also for titanium alloys.

It should be noted that the crack initiation and growth for VHCF, especially for the cases of crack initiation from the interior of specimen, is a three dimensional problem. This aspect is less reported in VHCF literature and may be referred to some recent results about the three dimensional analyses on the trend of stress intensity factors at crack tip [94,95].

\section{Concluding remarks}

\subsection{Characteristics and mechanism of VHCF for metallic materials}

(1) VHCF crack initiation is commonly from the interior of material (specimen) with the feature of an FiE containing an FGA. It is regarded that FGA in high-strength steels (or RA in titanium alloys) is the intrinsically characteristic region for crack initiation of VHCF.

(2) The value of $\Delta K_{\mathrm{FGA}}$ almost keeps constant tending to the crack growth threshold $\Delta K_{\mathrm{th}}$ for a given material, and $\Delta K_{\mathrm{FGA}}$ is a function of Burgers vector and shear modulus of material. Thus $a_{\mathrm{FGA}}$ and $\Delta K_{\mathrm{FGA}}$ are regarded as the intrinsically characteristic quantities of crack initiation for VHCF. 
(3) The size of FGA is only tens of microns and this crack initiation region takes more than $95 \%$ of total fatigue life. The crack growth rate in FGA is as low as $10^{-12}$ and $10^{-13} \mathrm{~m} / \mathrm{cyc}$.

(4) The nature of FGA is a layer of nanograins, which exists in the both sides of crack surfaces of FGA region.

(5) The formation mechanism of FGA is due to the Numerous Cyclic Pressing (NCP) in the originated crack wake resulting in the grain refinement on the crack surfaces during crack initiation process.

(6) The NCP model explains the nature of crack interior initiation for VHCF and is verified by further experimentations. The NCP concept also provides an insightful clue for producing metallic thin film with nano-sized microstructure.

\subsection{Other topics concerned in VHCF field}

This overview focuses on the topics of the crack initiation characteristics and the formation mechanism of crack initiation region for VHCF. There are other important topics of VHCF, which are less described in this overview.

(1) The model to predict or estimate the fatigue life and/or fatigue strength is an important topic of VHCF research, which includes the loading stress ratio effect and the specimen size effect on the VHCF behavior. This topic may be referred to [52,64,67,96-103].

(2) The type and the shape of inclusion may affect the crack initiation process, and for some cases, fatigue crack interior initiation may from other inhomogeneities like grain boundaries rather than inclusions. This topic may be referred to $[17,18,73,81,82]$.

(3) The use of ultrasonic frequency makes the testing of $10^{9}$ cycles be easily accomplished within $15 \mathrm{~h}$, but the effect of frequency on VHCF behavior of metallic materials is always a concerned issue. This article cited quite a number of data via ultrasonic frequency testing, but the frequency effect is less addressed. This topic may be referred to $[22,49,104]$.

(4) The effect of loading environment on the VHCF behavior of metallic materials is also a concerned topic. The related importance is due to the specific mechanism in relation to the very-high-cycle corrosion fatigue and to the fact that engineering components are inevitably emerged in a certain kind of environment. The effect of mild corrosion medium on VHCF property can be very remarkable. This topic may be referred to $[22,105,106]$.

\subsection{Prospective issues of VHCF research}

(1) It is essential to reveal the evolution process of crack initiation and early growth for VHCF: by taking the advantage of state of the art experimental equipment and techniques to design unique testing method, thus to explore the microprocess of crack initiation and early growth for VHCF. It is anticipated that the explicit revelation for the process of crack initiation and early growth will be a breakthrough of VHCF research.

(2) It is necessary to develop the physical-mechanism-based mechanics models for VHCF: in the light of physical mechanisms such as the micro-mechanism of microstructure evolution due to loading condition and that of defect formation and growth, to establish the mechanics model so that to quantitatively describe the damage behavior and fatigue property of VHCF.

(3) As known, the research of VHCF for metallic materials has been almost restricted to the testing methods of mode I loading. The topic of VHCF behavior for metallic materials under mix-mode loading could be a new branch in VHCF area. It is evident that, under remote mix-mode loading or even for remote mode I loading, the state of crack initiation and early growth for VHCF is a three dimensional case, which is an important issue of in-depth investigation.

(4) The effects of loading frequency and loading environment on the behavior of VHCF require further investigation. Although there have been some results in the literature, it is still at the development stage of data cumulation. The roles of the related factors in the frequency effect and in the corrosionfatigue process, respectively, have not been clearly identified. On the other hand, the loading frequency effect and the loading environment effect are always the questions to be answered in engineering applications.

\section{Acknowledgements}

The authors would like to appreciate the financial supports from the National Natural Science Foundation of China (11572325) and from the Strategic Priority Research Program of the Chinese Academy of Sciences (XDB22040503, XDB22020201).

\section{References}

[1] S.E. Stanzl, E.K. Tschegg, H. Mayer, Lifetime measurements for random loading in the very high cycle fatigue range, Int. J. Fatigue 8 (1986) 195-200.

[2] P. Lukáš, L. Kunz, Specific features of high-cycle and ultra-high-cycle fatigue, Fatigue Fract. Eng. Mater. Struct. 25 (2002) 747-753.

[3] Y. Murakami, N.N. Yokoyama, J. Nagata, Mechanism of fatigue failure in ultralong life regime, Fatigue Fract. Eng. Mater. Struct. 25 (2002) 735-746.

[4] C. Bathias, P.C. Paris, Gigacycle fatigue in mechanical practice, Marcel Dekker, New York, 2005.

[5] ASTM E468-90, 2004, Annual book of ASTM standards 2006, Section 3, vol. 03.01, p. 556-561.

[6] M. Kikukawa, K. Ohji, K. Ogura, Push-pull fatigue strength of mild steel at very high frequencies of stress up to $100 \mathrm{kc} / \mathrm{s}$, Trans. ASME J. Basic Eng. 87 (1965) $857-864$.

[7] T. Naito, H. Ueda, M. Kikuchi, Observation of fatigue fracture surface of carburized steel, J. Soc. Mater. Sci. 32 (1983) 1162-1166.

[8] T. Naito, H. Ueda, M. Kikuchi, Fatigue behavior of carburized steel with internal oxides and nonmartensitic microstructure near the surface, Metall Trans. A 15A (1984) 1431-1436.

[9] A. Atrens, W. Hoffelner, T.W. Duerig, J.E. Allison, Subsurface crack initiation in high cycle fatigue in Ti6Al4V and in a typical martensitic stainless steel, Scripta Metall. 17 (1983) 601-606.

[10] A. Wöhler, Wöhler's experiments on the strength of metals, Engineering 4 (1867) 160-161.

[11] U. Zerbst, S. Beretta, G. Koehler, A. Lawton, M. Vormwald, H. Th Beier, C. Klinger, I. Cerny, J. Rudlin, T. Heckel, D. Klingbeil, Safe life and damage tolerance aspects of railway axles - a review, Eng. Fract. Mech. 98 (2013) 214-271.

[12] W.P. Mason, Internal friction and fatigue in metals at large strain amplitudes, J. Acoust. Soc. Am. 28 (1956) 1207-1218.

[13] L.E. Willertz, Ultrasonic fatigue, Int. Metals Rev. 25 (2) (1980) 65-78.

[14] J.M. Wells, O. Buck, L.D. Roth, J.K. Tien, Ultrasonic fatigue, in: Proceedings of the first international conference on fatigue and corrosion fatigue up to ultrasonic frequencies, The Metallurgical Society of AIME. New York, 1982.

[15] J.K. Tien, The state of ultrasonic fatigue, ultrasonic fatigue, Proceedings of the first international conference on fatigue and corrosion fatigue up to ultrasonic frequencies, The Metallurgical Society of AIME, New York, 1982.

[16] K. Asami, Y. Sugiyama, Fatigue strength of various surface hardened steels, J. Japan Soc. Heat Treatment 25 (3) (1985) 147-150.

[17] S.X. Li, Effects of inclusions on very high cycle fatigue properties of high strength steels, Int. Mater. Rev. 57 (2012) 92-114.

[18] M. Zimmermann, Diversity of damage evolution during cyclic loading at very high numbers of cycles, Int. Mater. Rev. 57 (2012) 73-91.

[19] C.P. Przybyla, W.D. Musinski, G.M. Castelluccio, D.L. McDowell Microstructure-sensitive HCF and VHCF simulations, Int. J. Fatigue 57 (2013) 9-27.

[20] S. Stanzl-Tschegg, Very high cycle fatigue measuring techniques, Int. J. Fatigue 60 (2014) 2-17.

[21] C.S. Bandara, S.C. Siriwardane, U.I. Dissanayake, R. Dissanayake, Fatigue failure predictions for steels in the very high cycle region - a review and recommendations, Eng. Fail. Anal. 45 (2014) 421-435.

[22] H. Mayer, Recent developments in ultrasonic fatigue, Fatigue Fract. Eng. Mater. Struct. 39 (2016) 3-29. 
[23] T. Sakai, A. Nakagawa, N. Oguma, Y. Nakamura, A. Ueno, S. Kikuchi, A. Sakaida, A review on fatigue fracture modes of structural metallic materials in very high cycle regime, Int. J. Fatigue 60 (2016) 339-351.

[24] K. Asami, H. Emura, Fatigue strength characteristics of high-strength steel, JSME Int. J. Ser. I-Solid Mech. Strength Mater. 33 (1990) 367-374.

[25] S. Nishijima, K. Kanazawa, Stepwise S-N curve and fish-eye failure in gigacycle fatigue, Fatigue Fract. Eng. Mater. Struct. 22 (1999) 601-607.

[26] T. Sakai, M. Takeda, K. Shiozawa, Ochi Y, M. Nakajima, T. Nakamura, N. Oguma, Experimental reconfirmation of characteristic S-N property for high carbon chromium bearing steel in wide life region in rotating bending, J. Soc. Mater. Sci. 49 (7) (2000) 779-785.

[27] T. Sakai, Review and prospects for current studies on very high cycle fatigue of metallic materials for machine structural use, J. Solid Mech. Mater. Eng. 3 (2009) 425-439.

[28] T. Sakai, Y. Sato, N. Oguma, Characteristic S-N properties of high-carbonchromium-bearing steel under axial loading in long-life fatigue, Fatigue Fract. Eng. Mater. Struct. 25 (2002) 765-773.

[29] K. Shiozawa, L. Lu, S. Ishihara, S-N curve characteristics and subsurface crack initiation behaviour in ultra-long life fatigue of a high carbon-chromium bearing steel, Fatigue Fract. Eng. Mater. Struct. 24 (2001) 781-790.

[30] Y. Ochi, T. Matsumura, K. Masaki, S. Yoshida, High-cycle rotating bending fatigue property in very long-life regime of high-strength steels, Fatigue Fract. Eng. Mater. Struct. 25 (2002) 823-830.

[31] Y. Hong, A. Zhao, G. Qian, C. Zhou, Fatigue strength and crack initiation mechanism of very-high-cycle fatigue for low alloy steels, Metall. Mater. Trans. A 43 (2012) 2753-2762.

[32] K. Shiozawa, Y. Morii, S. Nishino, Subsurface crack initiation and propagation mechanism under the super-long fatigue regime for high speed tool steel (JIS SKH51) by fracture surface topographic analysis, JSME Int, J. Ser. A-Solid Mech. Mat. Eng. 49 (1) (2006) 1-10.

[33] K. Shiozawa, Y. Morii, S. Nishino, L. Lu, Subsurface crack initiation and propagation mechanism in high strength steel in a very high cycle fatigue regime, Int. J. Fatigue 28 (2006) 1521-1532.

[34] G. Qian, PhD Thesis: experimental investigation on high cycle and very-highcycle fatigue behavior of low alloy steel under different environmental media Institute of Mechanics, Chinese Academy of Sciences, 2009 (In Chinese).

[35] J.H. Zuo, Z.G. Wang, E.H. Han, Effect of microstructure on ultra-high cycle fatigue behavior of Ti-6Al-4V, Mater. Sci. Eng. A 473 (2008) 147-152.

[36] C.J. Szczepanski, S.K. Jha, J.M. Larsen, J.W. Jones, Microstructural influences on very high cycle fatigue crack initiation in Ti-6246, Metall. Mater. Trans. A 39 (2008) 2841-2851.

[37] H. Oguma, T. Nakamura, The effect of microstructure on very high cycle fatigue properties in Ti-6Al-4V, Scr. Mater. 63 (2010) 32-34.

[38] S. Heinz, F. Balle, G. Wagner, D. Eifler, Analysis of fatigue properties and failure mechanisms of Ti6Al4V in the very high cycle fatigue regime using ultrasonic technology and 3D laser scanning vibrometry, Ultrasonics 53 (2013) 1433-1440.

[39] E. Takeuchi, Y. Furuya, N. Nagashima, S. Matsuoka, The effect of frequency on the giga-cycle fatigue properties of a Ti-6Al-4V alloy, Fatigue Fract. Eng. Mater. Struct. 31 (2008) 599-605.

[40] Y. Furuya, E. Takeuchi, Gigacycle fatigue properties of Ti-6Al-4V alloy under tensile mean stress, Mater. Sci. Eng. A 598 (2014) 135-140.

[41] X. Liu, C. Sun, Y. Hong, Effects of stress ratio on high-cycle and very-highcycle fatigue behavior of a Ti-6Al-4V alloy, Mater. Sci. Eng. A 622 (2015) $228-235$.

[42] X. Liu, C. Sun, Y. Zhou, Y. Hong, Effects of microstructure and stress ratio on high-cycle and very-high-cycle fatigue of Ti-6Al-4V alloy, Acta Metall. Sin. 52 (2016) 923-930.

[43] Y. Hong, Z. Lei, C. Sun, A. Zhao, Propensities of crack interior initiation and early growth for very-high-cycle fatigue of high strength steels, Int. J. Fatigue 58 (2014) 144-151.

[44] Y. Murakami, S. Kodama, S. Konuma, Quantitative evaluation of effects of non-metallic inclusions on fatigue strength of high strength steels. I: Basic fatigue mechanism and evaluation of correlation between the fatigue fracture stress and the size and location of non-metallic inclusions, Int. J. Fatigue 11 (1989) 291-298.

[45] B. Atzori, P. Lazzarin, G. Meneghetti, A unified treatment of the mode I fatigue limit of components containing notches or defects, Int. J. Fract. 133 (2005) 61-87.

[46] T. Sakai, M. Takeda, N. Tanaka, M. Kanemitsu, N. Oguma, K. Shiozawa, S-N property and fractography of high carbon chromium bearing steel over ultra wide life region under rotating bending, Transactions of the Japan Society of Mechanical Engineers 67A (2001) 1805-1812.

[47] K. Shiozawa, L. Lu, Very high-cycle fatigue behaviour of shot-peened highcarbon-chromium bearing steel, Fatigue Fract. Eng. Mater. Struct. 25 (2002) $813-822$.

[48] A. Zhao, J. Xie, C. Sun, Y. Hong, Prediction of threshold value for FGA formation, Mater. Sci. Eng. A 528 (2011) 6872-6877.

[49] A. Zhao, J. Xie, C. Sun, Y. Hong, Effects of strength level and loading frequency on very-high-cycle fatigue behavior for a bearing steel, Int. J. Fatigue 38 (2012) 46-56.

[50] Y.D. Li, Z.G. Yang, S.X. Li, Y.B. Liu, S.M. Chen, Correlations between very high cycle fatigue properties and inclusions of GCr15 bearing steel, Acta Metall. Sin. 44 (2008) 968-972.

[51] W. Li, T. Sakai, Q. Li, L.T. Lu, P. Wang, Reliability evaluation on very high cycle fatigue property of GCr15 bearing steel, Int. J. Fatigue 32 (2010) 1096-1107.
[52] Y.B. Liu, Y.D. Li, S.X. Li, Z.G. Yang, S.M. Chen, W.J. Hui, Y.Q. Weng, Prediction of the S-N curves of high-strength steels in the very high cycle fatigue regime, Int. J. Fatigue 32 (2010) 1351-1357.

[53] R.W. Hertzberg, R.P. Vinci, J.L. Hertzberg, Deformation and fracture mechanics of engineering materials, 5th ed., Wiley, New York, 2012.

[54] W.D. Nix, H.J. Gao, Indentation size effects in crystalline materials: a law for strain gradient plasticity, J. Mech. Phys. Solids 46 (1998) 411-425.

[55] Z.G. Yang, S.X. Li, Y.B. Liu, Y.D. Li, G.Y. Li, W.J. Hui, Y.Q. Weng, Estimation of the size of GBF area on fracture surface for high strength steels in very high cycle fatigue regime, Int. J. Fatigue 30 (2008) 1016-1023.

[56] Z. Lei, J. Xie, C. Sun, Y. Hong, Effect of loading condition on very-high-cycle fatigue behavior and dominant variable analysis, Sci. China Phys. Mech. Astron. 57 (2014) 74-82.

[57] P.C. Paris, H. Tada, J.K. Donald, Service load fatigue damage - a historical perspective, Int. J. Fatigue 21 (1999) S35-S46.

[58] M. Papakyriacou, H. Mayer, U. Fuchs, S.E. Stanzl-Tschegg, R.P. Wei, Influence of atmospheric moisture on slow fatigue crack growth at ultrasonic frequency in aluminium and magnesium alloys, Fatigue Fract. Eng. Mater. Struct. 25 (2002) 795-804.

[59] B. Holper, H. Mayer, A.K. Vasudevan, S.E. Stanzl-Tschegg, Near threshold fatigue crack growth at positive load ratio in aluminium alloys at low and ultrasonic frequency: influences of strain rate, slip behaviour and air humidity, Int. J. Fatigue 26 (2004) 27-38.

[60] L.P. Borrego, J.M. Costa, S. Silva, J.M. Ferreira, Microstructure dependent fatigue crack growth in aged hardened aluminium alloys, Int. J. Fatigue 26 (2004) 1321-1331.

[61] X. Huang, T. Moan, Improved modeling of the effect of R-ratio on crack growth rate, Int. J. Fatigue 29 (2007) 591-602.

[62] R.O. Ritchie, D.L. Davidson, B.L. Boyce, J.P. Campbell, O. Roder, High-cycle fatigue of Ti-6Al-4V, Fatigue Fract. Eng. Mater. Struct. 22 (1999) 621-631.

[63] J. Petit, C. Sarrazin-Baudoux, An overview on the influence of the atmosphere environment on ultra-high-cycle fatigue and ultra-slow fatigue crack propagation, Int. J. Fatigue 28 (2006) 1471-1478.

[64] Q.Y. Wang, J.Y. Berard, S. Rathery, C. Bathias, High-cycle fatigue crack initiation and propagation behaviour of high-strength spring steel wires, Fatigue Fract. Eng. Mater. Struct. 22 (1999) 673-677.

[65] Y. Murakami, T. Nomoto, T. Ueda, Y. Murakami, On the mechanism of fatigue failure in the superlong life regime $\left(\mathrm{N}>10^{7}\right.$ cycles), Part II: a fractographic investigation, Fatigue Fract. Eng. Mater. Struct. 23 (2000) 903-910.

[66] K. Tanaka, Y. Akiniwa, Fatigue crack propagation behaviour derived from S-N data in very high cycle regime, Fatigue Fract. Eng. Mater. Struct. 25 (2002) 775-784.

[67] Y. Murakami, T. Nomoto, T. Ueda, Factors influencing the mechanism of superlong fatigue failure in steels, Fatigue Fract. Eng. Mater. Struct. 22 (1999) 581-590.

[68] K. Tanaka, T. Mura, A theory of fatigue crack initiation at inclusions, Metall. Trans. A 13A (1982) 117-123.

[69] H. Su, X. Liu, C. Sun, Y. Hong, Nanograin layer formation at crack initiation region for very-high-cycle fatigue of a Ti-6Al-4V alloy, Fatigue Fract. Eng. Mater. Struct 40 (2017) 979-993.

[70] S.E. Stanzl-Tschegg, B. Schonbauer, Near-threshold crack propagation and internal cracks in steel, Procedia Eng. 2 (2010) 1547-1555.

[71] W. Ishida, T. Yamamoto, S. Kaneda, T. Ogawa, Fatigue strength and internal crack growth behavior of high strength steel under variable amplitude stressing in very high cycle regime, Trans. Japan Soc. Mech. Eng. A 78 (2012) 23-33.

[72] T. Ogawa, S. Stanzl-Tschegg, B. Schonbauer, A fracture mechanics approach to interior fatigue crack growth in the very high cycle regime, Eng. Fract. Mech. 115 (2014) 241-254.

[73] M. Sander, T. Müller, J. Lebahn, Influence of mean stress and variable amplitude loading on the fatigue behaviour of a high-strength steel in VHCF regime, Int. J. Fatigue 62 (2014) 10-20.

[74] M. Sander, T. Müller, C. Stäcker, Very high cycle fatigue behavior under constant and variable amplitude loading, Procedia Struct. Integrity 2 (2016) 34-41.

[75] Y. Murakami, T. Nomoto, T. Ueda, Y. Murakami, On the mechanism of fatigue failure in the superlong life regime $\left(\mathrm{N}>10^{7}\right.$ cycles), Part I: influence of hydrogen trapped by inclusions, Fatigue Fract. Eng. Mater. Struct. 23 (2000) 893-902.

[76] K. Takai, J. Seki, Y. Honma, Observation of trapping sites of hydrogen and deuterium in high-strength steels by using secondary ion mass spectrometry, Mater. Trans. JIM 36 (1995) 1134-1139.

[77] K. Takai, Y. Honma, K. Izutsu, M. Nagumo, Identification of trapping sites in high-strength steels by secondary ion mass spectrometry for thermally desorbed hydrogen, J. Japan Institute Metals 60 (1996) 1155-1162.

[78] W.J. Hui, C. Chou, Y.J. Zhang, X.L. Zhao, H. Dong, Very high cycle fatigue properties of high-strength spring steel 60SiCrV7, Fatigue Fract. Eng. Mater. Struct. 39 (2016) 1081-1091.

[79] N. Oguma, H. Harada, T. Sakai, Mechanism of long life fatigue fracture induced by interior inclusion for bearing steel in rotating bending, J.Soc. Mater. Sci. 52 (2003) 1292-1297.

[80] T. Sakai, N. Oguma, A. Morikawa, Microscopic and nanoscopic observations of metallurgical structures around inclusions at interior crack initiation site for a bearing steel in very high-cycle fatigue, Fatigue Fract. Eng. Mater. Struct. 38 (2015) 1305-1314. 
[81] G.C. Chai, T. Forsman, F. Gustavsson, C. Wang, Formation of fine grained area in martensitic steel during very high cycle fatigue, Fatigue Fract. Eng. Mater. Struct. 38 (2015) 1315-1323.

[82] G.C. Chai, Analysis of microdamage in a nickel-base alloy during very high cycle fatigue, Fatigue Fract. Eng. Mater. Struct. 39 (2016) 712-721.

[83] P. Grad, B. Reuscher, A. Brodyanski, M. Kopnarski, E. Kerscher, Mechanism of fatigue crack initiation and propagation in the very high cycle fatigue regime of high-strength steels, Scripta Mater. 67 (2012), 838-641.

[84] A.A. Shanyavskiy, Mechanisms and modeling of subsurface fatigue cracking in metals, Eng. Fract. Mech. 110 (2013) 350-363.

[85] H. Oguma, T. Nakamura, Fatigue crack propagation properties of Ti-6Al-4V in vacuum environments, Int. J. Fatigue 50 (2013) 89-93.

[86] S. Kovacs, T. Beck, L. Singheiser, Influence of mean stresses on fatigue life and damage of a turbine blade steel in the VHCF-regime, Int. J. Fatigue 49 (2013) 90-99.

[87] Y. Hong, X. Liu, Z. Lei, C. Sun, The formation mechanism of characteristic region at crack initiation for very-high-cycle fatigue of high-strength steels, Int. J. Fatigue 89 (2016) 108-118.

[88] D.B. Williams, C.B. Carter, Transmission electron microscopy: a textbook for materials science, 2nd ed., Springer, New York, 2009.

[89] R. Pippan, A. Hohenwarter, Fatigue crack closure: a review of the physical phenomena, Fatigue Fract. Eng. Mater. Struct. 40 (2017) 471-495.

[90] M. Farahani, I. Sattari-Far, D. Akbari, R. Alderliesten, Effect of residual stresses on crack behaviour in single edge bending specimens, Fatigue Fract. Eng. Mater. Struct. 36 (2013) 115-126.

[91] R. Valiev, Nanostructuring of metals by severe plastic deformation for advanced properties, Nat. Mater. 3 (2004) 511-516.

[92] Y. Estrin, A. Vinogradov, Extreme grain refinement by severe plastic deformation: a wealth of challenging science, Acta Mater. 61 (2013) 782-817.

[93] Q. Jiang, C. Sun, X. Liu, Y. Hong, Very-high-cycle fatigue behavior of a structural steel with and without induced surface defects, Int. J. Fatigue 93 (2016) 352-362.

[94] L.P. Pook, A. Campagnolo, F. Berto, Coupled fracture modes of discs and plates under anti-plane loading and a disc under in-plane shear loading, Fatigue Fract. Eng. Mater. Struct. 39 (2016) 924-938.
[95] Z. He, A. Kotousov, F. Berto, Effect of vertex singularities on stress intensities near plate free surfaces, Fatigue Fract. Eng. Mater. Struct. 38 (2015) 860-869.

[96] M.D. Chapetti, T. Tagawa, T. Miyata, Ultra-long cycle fatigue of high-strength carbon steels part II: estimation of fatigue limit for failure from internal inclusions, Mater. Sci. Eng. A 356 (2003) 236-244.

[97] H. Mughrabi, Cyclic slip irreversibilities and the evolution of fatigue damage, Metall. Mater. Trans. A 40A (2009) (2009) 1257-1279.

[98] H. Mayer, W. Haydn, R. Schuller, S. Issler, B. Furtner, M. Bacher-Höchst, Very high cycle fatigue properties of bainitic high carbon-chromium steel, Int. J. Fatigue 31 (2009) (2009) 242-249.

[99] C. Sun, X. Liu, Y. Hong, A two-parameter model to predict fatigue life of highstrength steels in a very high cycle fatigue regime, Acta Mech. Sinica 31 (2015) 383-391.

[100] C. Sun, X. Zhang, X. Liu, Y. Hong, Effects of specimen size on fatigue life of metallic materials in high-cycle and very-high-cycle fatigue regimes, Fatigue Fract. Eng. Mater. Struct. 39 (2016) 770-779.

[101] Z.Y. Huang, H.Q. Liu, C. Wang, Q.Y. Wang, Fatigue life dispersion and therma dissipation investigations for titanium alloy TC17 in very high cycle regime, Fatigue Fract. Eng. Mater. Struct. 38 (2015) (2015) 1285-1293.

[102] I. Marines-Garcia, P.C. Paris, H. Tada, C. Bathias, Fatigue crack growth from small to long cracks in very-high-cycle fatigue with surface and internal "fish-eye" failures for ferrite-perlitic low carbon steel SAE 8620, Mater. Sci. Eng. A 468-470 (2007) 120-128.

[103] D.S. Paolino, A. Tridello, G. Chiandussi, M. Rossetto, Statistical distributions of Transition Fatigue Strength and Transition Fatigue Life in duplex S-N fatigue curves, Theor. Appl. Fract. Mech. 80 (2015) 31-39.

[104] N. Schneider, J. Bödecker, C. Berger, M. Oechsner, Frequency effect and influence of testing technique on the fatigue behaviour of quenched and tempered steel and aluminium alloy, Int. J. Fatigue 93 (2016) 224-231.

[105] G. Qian, C. Zhou, Y. Hong, A model to predict S-N curves for surface and subsurface crack initiations in different environmental media, Int. J. Fatigue 71 (2015) 35-44.

106] S.X. Li, P.Y. Zhang S.R. Yu, Experimental study on very high cycle fatigue of martensitic steel of $2 \mathrm{Cr} 13$ under corrosive environment, Fatigue Fract. Eng. Mater. Struct. 37 (2014) 1146-1152. 